This is the final peer-reviewed accepted manuscript of

Lanari P.; Giuntoli F.; Loury C.; Burn M.; Engi M.: An inverse modeling approach to obtain P-T conditions of metamorphic stages involving garnet growth and resorption. EUROPEAN JOURNAL OF MINERALOGY 29. 0935-1221

DOI: $10.1127 /$ ejm/2017/0029-2597

The final published version is available online at:

http://dx.doi.org/10.1127/ejm/2017/0029-2597

Rights / License:

The terms and conditions for the reuse of this version of the manuscript are specified in the publishing policy. For all terms of use and more information see the publisher's website.

This item was downloaded from IRIS Università di Bologna (https://cris.unibo.it/)

When citing, please refer to the published version. 


\title{
An inverse modeling approach to obtain $P-T$ conditions of metamorphic stages involving garnet growth and resorption
}

\author{
Pierre LANARI ${ }^{1, *}$, FrANCESCO GIUNTOLI $^{1}$, ChloÉ LOURY $^{2}$, MARCO BURN $^{1}$ and MARTIN ENGI ${ }^{1}$ \\ ${ }^{1}$ Institute of Geological Sciences, University of Bern, Baltzerstrasse 3, 3012 Bern, Switzerland \\ *Corresponding author: e-mail: pierre.lanari@geo.unibe.ch \\ ${ }^{2}$ Géoazur, Observatoire de la Côte d'Azur, Université de Nice Sophia-Antipolis, 250 rue A. Einstein, 06560
}

Valbonne, France

\begin{abstract}
This contribution presents an approach and a computer program (GRTMOD) for numerical simulation of garnet evolution based on compositions of successive growth zones in natural samples. For each garnet growth stage, a new local effective bulk composition is optimized, allowing for resorption and/or fractionation of previously crystallized garnet. The successive minimizations are performed using the Nelder Mead algorithm; a heuristic search method. An automated strategy including two optimization stages and one refinement stage is described and tested. This program is used to calculate pressure temperature $(P T)$ conditions of crystal growth as archived in garnet from the Sesia Zone (Western Alps). The compositional variability of successive growth zones is characterized using standardized X ray maps and the program XMapTools. The model suggests that Permian garnet cores crystallized under granulite facies conditions at $T>800{ }^{\circ} \mathrm{C}$ and $P=6 \mathrm{kbar}$. During Alpine times, a first garnet rim grew at eclogite facies conditions $\left(650^{\circ} \mathrm{C}, 16 \mathrm{kbar}\right)$ at the expense of the garnet core. A second rim was added at lower $P(\sim 11 \mathrm{kbar})$ and 630 ${ }^{\circ} \mathrm{C}$. In total, garnet resorption is modeled to amount to $\sim 9$ vol\% during the Alpine evolution; this value is supported by our observations in X ray compositional maps.
\end{abstract}

Key-words: thermodynamic modeling; garnet; resorption; X ray mapping; XMapTooLs.

\section{Introduction}

An inverse approach to a scientific problem involves the determination of the causal factors that satisfy a set of observations. In metamorphic rocks of a given bulk-rock composition $\left(C_{\mathrm{BR}}\right)$, pressure $(P)$ and temperature $(T)$ conditions determine the stable mineral assemblage, thus they constitute the causal factors. In this case, observations are the coexisting phases defining the mineral assemblage, their compositions and volume proportions. However, Gibbs free energy minimization, the method classically used to model such an assemblage, is a forward technique (e.g., de Capitani \& Petrakakis, 2010). Resulting equili-brium phase diagrams are strictly based on assemblages predicted by Gibbs free energy minimization for a given $C_{\mathrm{BR}}$, i.e., the composition of a rock volume devoid of compositional heterogeneities. Such diagrams combined with mineral isopleths have been intensively used to estimate $P-T$ conditions in metamorphic rocks by comparing results of the model with observations.

Porphyroblasts are large crystals surrounded by a matrix of finer-grained minerals and are of central interest because they often preserve a chemical and textural record of metamorphic processes and conditions. For instance, garnet porphyroblast in low- to moderate-grade metamorphic rocks often are compositionally zoned, and in favorable cases such zoning can be used to infer the part of the $P-T$ history during which garnet grew in a sample (e.g., Spear \& Selverstone 1983; Spear et al., 1984, 1991a; Konrad-Schmolke et al., 2005; Gaidies et al., 2006, 2008b; Cheng \& Cao, 2015). This method works for relatively large garnet crystals provided that metamorphic duration is not unusually long and that thermal maximum reached by the sample was below $\sim 700{ }^{\circ} \mathrm{C}$. In such cases, intracrystalline diffusion is slow enough (Yardley, 1977; Caddick et al., 2010; Stowell et al., 2011) to preserve fine compositional differences, and the compositional zoning in garnet is likely to reflect growth conditions. However, variations in $P-T$ conditions and isolation of early garnet growth zones imply a gradual change in $C_{\mathrm{BR}}$ of the reactive part of the rock (Evans, 2004). In cases where a significant amount of compositionally zoned garnet is preserved $(>2-3 \quad v o l \%)$, a single equilibrium phase diagram cannot be used to retrieve successive $P-T$ stages. During the last 25 years four main approaches were developed to overcome this problem, all of which are essentially based on thermodynamic equilibrium theory: DiffGibbs program (Spear et al., 1991b) allows for prediction of the chemical-zoning pattern of garnet. It accounts for intragranular diffusion in garnet operating simultaneously with net-transfer and exchange reactions during garnet growth. Along a specific $P-T$ trajectory, 
garnet is assumed to be in equilibrium with a given set of phases. The limit of this approach is that it does not test the stability of the assemblage for the given $C_{\mathrm{BR}}$.

- The second approach consists of successive forward models for which $C_{\mathrm{BR}}$ is manually altered to account for material sequestered in garnet cores, as analyzed and mapped by electron microprobe (Marmo et al., 2002; Tinkham \& Ghent, 2005; Caddick et al., 2007).

- Forward modeling of garnet zoning and coexisting phases (including mineral modes) is realized for an arbitrary $P-T$ path using Gibbs free energy minimization, eventually comparing at each stage the predicted composition of garnet with the observed zoning (e.g., Konrad-Schmolke et al., 2008; Robyr et al., 2014). Garnet compositions and volumes produced at each step are fractionated from the $C_{\mathrm{BR}}$, thus providing a new effective bulk composition. That composition refers to the volume domain in the rock over which thermodynamic equilibrium is established during one increment of garnet growth. The first limitation of such models is the arbitrary choice of the $P-T$ trajectory. To improve the results of such models, Moynihan \& Pattison (2013) provided an automated inverse strategy to derive the "best" $P-T$ trajectory by minimizing a misfit parameter, basically the weighted differences between measured and model compositional profiles. Once a $P-T$ point is found, a search begins for the next $P-T$ point, with a model composition that best matches the next point on the garnet transect. Similarly, Vrijmoed \& Hacker (2014) proposed a brute-force computational method (inverse technique as well) to determine the best $P-T$ trajectory by minimizing the differences between predicted and measured garnet compositional profiles along different trajectories. The fundamental limit of both Moynihan \& Pattison (2013) and Vrijmoed \& Hacker (2014) approaches is that garnet growth is assumed to occur continuously, and no garnet resorption is taken into account. In reality, part of the fractionating garnet may continue to react during the next $P-T$ point and to being dissolved. Evidence of garnet resorption is commonly visible in compositional maps (see, e.g., Figs. 3a,c and $4 \mathrm{a}$ in Moynihan \& Pattison, 2013). Again, this may produce significant changes in effective composition, depending on the amount resorbed, which is typically not visible in a sample.

- The program Theria G (Gaidies et al., 2008a) allows for numerical simulation of porphyroblast nucleation and garnet growth in a given volume of rock for any defined $P-T$-time $(P-T-t)$ path. Two major modules are used by Theria $G$, (1) the Gibbs free energy minimization routine of Theriak (de Capitani \& Brown, 1987) and (2) a model describing intragranular multi-component diffusion. In contrast to the previous techniques, Theria $G$ simulates the formation of an entire population of garnet with variable grain size using a forward model. The arbitrary choice of the $P-T$ trajectory is again a severe limitation of this model. However, Moynihan \& Pattison (2013) used the approach described above to derive the best $P-T$ trajectory, which is subsequently defined as input in Theria G models.
Addressing some of the limitations of existing approaches, this study proposes an alternative strategy and a computer program, GRTMOD (available at http:// grtmod.petrochronology.org), to model garnet growth during successive $P-T$ stages based on natural compositional records. To improve the control data, garnet compositions of successive growth zones are characterized from standardized X-ray maps (see details in Lanari et al., 2014). The $P-T$ conditions as well as proportions of garnet resorption are optimized by GRTMOD at each step to match the modeled and measured compositions. The model presented in this report differs from those reviewed above in that it is strongly based on the observation of preserved garnet growth zones in natural rocks; no provision for intracrystalline diffusion is made. GRTMOD is written in MATLAB ${ }^{\odot}$ and interacts with Theriak (de Capitani \& Brown, 1987) using the extension Theriak D (Duesterhoeft \& de Capitani, 2013).

\section{GRTMod strategy}

The strategy behind GRTMOD consists of using unconstrained nonlinear optimization to find the minimum of an objective function in $n$-dimensional space $(N \geq 2)$. The variables to be optimized are $P, T$, and, for stages $S^{i}(i>1)$, the volume fractions of all previous garnet growth zones that are fractionated from the $C_{\mathrm{BR}}$. These volume fractions may decrease in the course of modeling because of garnet resorption, which possibly affects the earlier growth zones to variable extents. The objective function used reflects the deviation of the model composition from the measured compositions. This approach critically relies on the characterization of the composition of successive garnet growth zones.

\subsection{Growth stages of garnet and corresponding variables}

As discussed in the introduction, in low- to moderate-grade metamorphic rocks $\left(T<700^{\circ} \mathrm{C}\right)$, for relatively large garnet crystals and assuming that metamorphic duration is not unusually long, intracrystalline diffusion is slow and the successive garnet compositions are likely to reflect changes in equilibrium conditions only. Basically, the absence of zoning caused by intracrystalline diffusion can be verified by sharp compositional boundaries between the successive growth zones (Figs. 1 and 2).

In the present study, the growth history of garnet is divided into discrete events, defined as "growth stages" $\left(S^{i}\right.$, $i=1, \ldots, n$, see Table 1). An individual growth stage is a short event occurring at given $P^{i}$ and $T^{i}$ during which a garnet volume fraction $v^{i}$ grows with a homogeneous composition $C_{\mathrm{grt}}^{i}$.

For any growth stage $S^{i}$, the variables to be optimized are its specific $P$ and $T\left(P^{i}\right.$ and $\left.T^{i}\right)$ as well as the volume fraction of previous garnet to be fractionated from the $C_{\mathrm{BR}}\left(v^{i, j} \quad 1, \ldots, v^{i, j}{ }^{i}{ }^{1}\right)$. The number of variables at stage $i$ thus is:

$N^{i}=2+(i-1)$. 
Table 1. Definitions of symbols used in text.

\begin{tabular}{|c|c|}
\hline$C_{\mathrm{BR}}$ & Bulk rock composition in oxide weight percentage \\
\hline$C_{\mathrm{LEB}}^{i}$ & $\begin{array}{l}\text { Local effective bulk composition in oxide weight } \\
\text { percentage }\end{array}$ \\
\hline$S^{i}$ & Growth stage $i$ \\
\hline$N^{i}$ & Number of variables to be optimized during stage $i$ \\
\hline$P_{i}, T_{i}$ & $\begin{array}{l}\text { Pressure and temperature conditions optimized for } \\
\text { stage } i\end{array}$ \\
\hline$v^{i}$ & Volume fraction of garnet produced during stage $i$ \\
\hline$v^{i, j}$ & $\begin{array}{l}\text { Volume fraction of garnet crystallized during stage } \\
j \text { and fractionated from } \mathrm{C}_{\mathrm{BR}} \text { at stage } i\end{array}$ \\
\hline$C_{g r t}^{i}$ & $\begin{array}{l}\text { Measured composition of garnet } G^{\prime} t_{i} \text { in oxide } \\
\text { weight percentage }\end{array}$ \\
\hline$r^{i, j}$ & Total resorption of $G r t_{j}$ at stage $i$ \\
\hline$r_{\text {grt }}$ & Total resorption of garnet \\
\hline$\rho_{g r t}^{i}$ & Density of $G r t_{i}$ \\
\hline$\rho_{\text {rock }}^{I-1-1}$ & Density of the rock at stage $i$ \\
\hline$\rho_{m t x}^{i-1}$ & $\begin{array}{l}\text { Density of the matrix (all phases excepted garnet) } \\
\text { at stage } i \quad 1\end{array}$ \\
\hline$f_{k}^{\text {measured }}$ & Fraction of end member $k$ as measured \\
\hline$f_{k}^{\text {model }}$ & Fraction of end member $k$ as modeled \\
\hline$\omega_{k}$ & Weighting factor \\
\hline$n_{k}$ & $\begin{array}{l}\text { Number of counts recorded for the element } \\
\text { corresponding to end member } k\end{array}$ \\
\hline$L_{0}$ & Loss function value (weighted) \\
\hline$C_{0}$ & Cost function value \\
\hline$C_{01, s}^{i}$ & $\begin{array}{l}\text { Cost function value of the solution } s \text { for stage } i \\
\quad \text { (optimization1) }\end{array}$ \\
\hline$C_{02, s}^{i}$ & $\begin{array}{l}\text { Cost function value of the solution } s \text { for stage } i \\
\quad \text { (optimization2) }\end{array}$ \\
\hline$T C_{0}$ & Tolerance on $C_{0}$ used during auto refinement \\
\hline$G_{1, r}^{i}$ & $\begin{array}{l}\text { Starting guess for stage } i \text { and minimization } r \\
\quad \text { (optimization } 1 \text { ) }\end{array}$ \\
\hline$G_{2, r}^{i}$ & $\begin{array}{l}\text { Starting guess for stage } i \text { and minimization } r \\
\quad \text { (optimization2) }\end{array}$ \\
\hline$S_{1, s}^{i}$ & Solution $s$ for stage $i$ (optimization1) \\
\hline$S_{2, s}^{l}$ & Solution $s$ for stage $i$ (optimization2) \\
\hline$S_{\text {best }}^{l}$ & Best solution selected for stage $i$ \\
\hline
\end{tabular}

For the first stage, the $C_{\mathrm{BR}}$ of the sample is assumed to be equal to the composition of the reactive part of the system; hence $C_{\mathrm{BR}}$ serves as input for the forward models. For subsequent stages $(i>1)$, the local effective bulk composition, $C_{\mathrm{LEB}}^{i}$, is calculated as follows:

$$
C_{\mathrm{LEB}}^{i}=\frac{C_{\mathrm{BR}}-\sum_{j=1}^{i} 1 v^{i, j} \frac{\rho_{\mathrm{grt}}^{i}}{\rho_{\mathrm{rock}}^{i-1}} C_{\mathrm{grt}}^{i}}{\left(1-\sum_{j=1}^{i 1} v^{i, j}\right) \frac{\rho_{\text {mtx }}^{i-1}}{\rho_{\mathrm{rock}}^{i-1}}},
$$

where $C_{\mathrm{grt}}^{i}$ is the measured composition (in oxide $\mathrm{wt} \%$ ) of the garnet growth zone $i ; \rho_{\text {grt }}^{i}$ is its model density, and $\rho_{\text {rock }}^{i} 1$ and $\rho_{\mathrm{mtx}}^{i} 1$ are the average rock density and matrix density (i.e., all phases except garnet) from the preceding stage; $v^{i, j}$ is the volume fraction of garnet crystallized during stage $j$ that is fractionated from the $C_{\mathrm{BR}}$ at stage $i$. As some garnet of stage $i$ is preserved in the present-day sample despite possible resorption, the following condition is applied by GRTMOD at each growth zone:

$0<v^{i, j} \leq v^{i} 1, j$
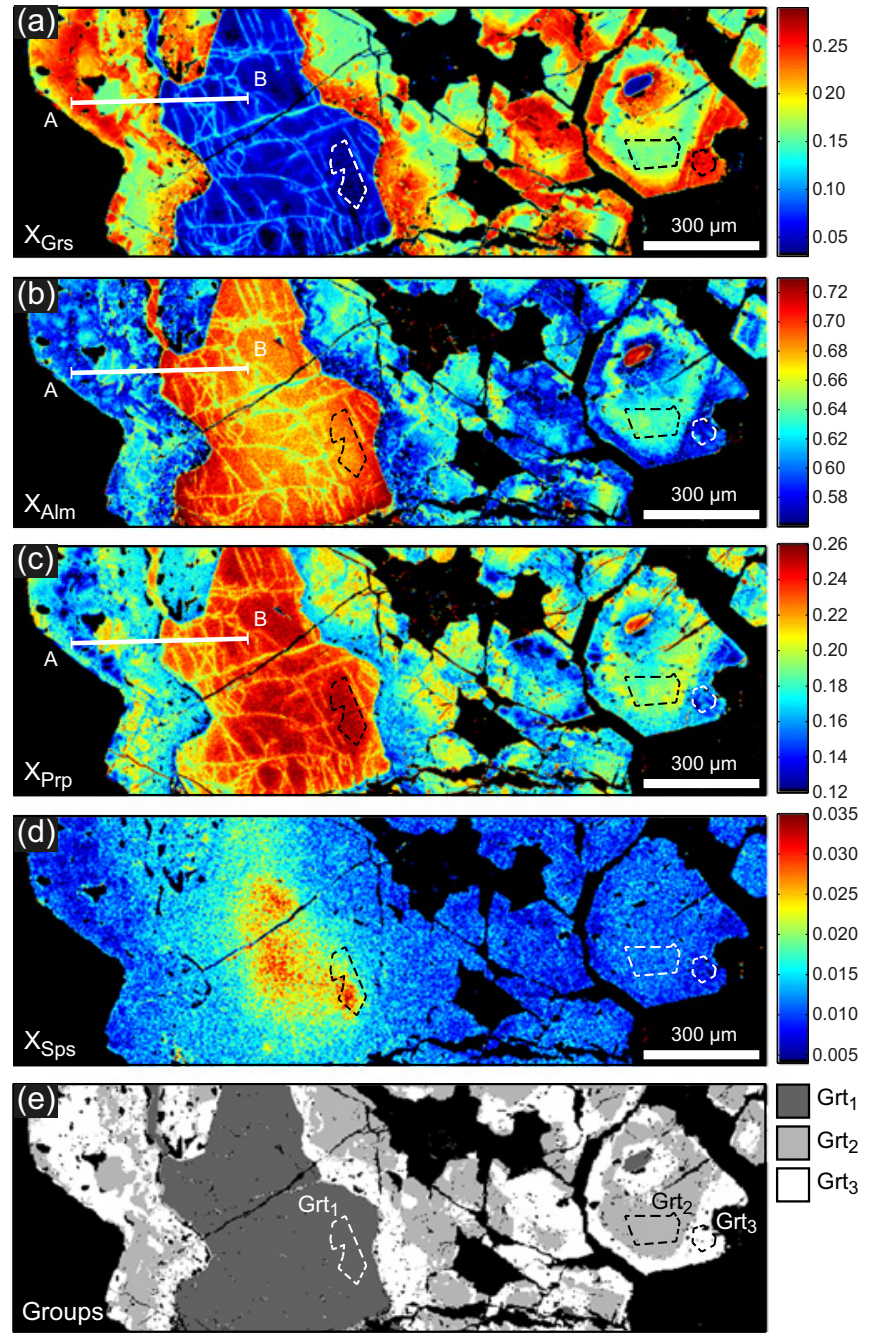

Fig. 1. Compositional maps of garnet in a polymetamorphic eclogitic micaschist from the Sesia Zone. Data obtained using XMapTools: maps of end member proportions generated using the external function Gar StructForm: (a) grossular; (b) almandine, (c) pyrope; (d) spessartine. (e) Maps of the compositional groups generated using the module Chem2d (Lanari et al., 2014). Domains used to derive the average composition of $\mathrm{Grt}_{1}, \mathrm{Grt}_{2}$ and $\mathrm{Grt}_{3}$ are outlined by dashed line. (Online version in color.)

The resorption of garnet $j$ at stage $i(i>j)$ is expressed in vol\% of garnet in the bulk rock and is given by:

$r^{i, j}=\left(v^{i} 1, j-v^{i, j}\right) \times 100$.

The total resorption of garnet $r_{\text {grt }}$ is defined as

$r_{\text {grt }}=\sum_{i} \sum_{j} r^{i, j}$

In order to compute the local effective bulk composition from garnet volume fractions - to fractionate the previous garnet from the $C_{\mathrm{BR}}$-the rock density of the previous stage is required (Eq. (2)). The density of the rock at stage $i-1$ ( $\left.\rho_{\mathrm{rock}}^{i}\right)$ is calculated assuming zero porosity:

$\rho_{\mathrm{rock}}^{i} 11=\sum_{j=1}^{i} v^{i, j} \rho_{\mathrm{grt}}^{i}+\rho_{\mathrm{mtx}}^{i 1}\left(1-\sum_{j=1}^{i} v^{1} v^{i, j}\right)$. 


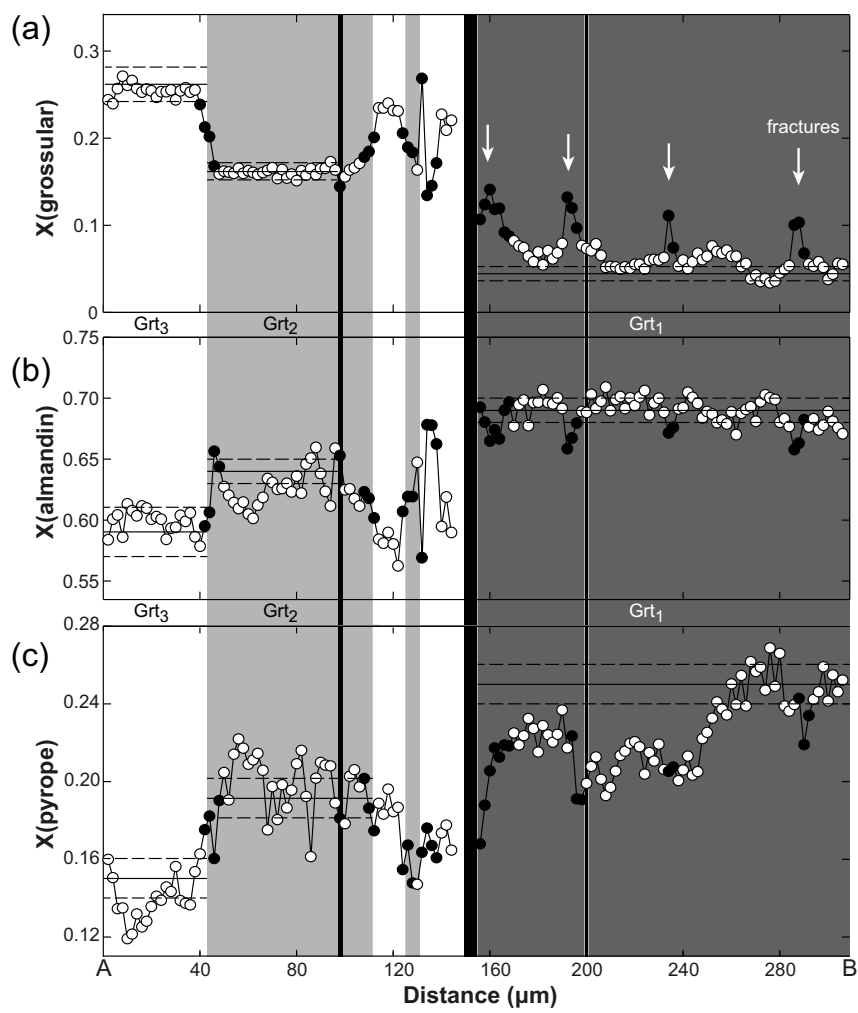

Fig. 2. Zoning profile of garnet end member proportions along $A B$ transect (see Fig. 1): (a) grossular; (b) almandine; (c) pyrope; note different scales. Fractures in garnet core $\left(\mathrm{Grt}_{1}\right)$ are indicated by white arrows in (a); the corresponding compositions are neglected in further calculations (black circles). Mean compositions of each garnet group are reported (solid black lines) together with standard deviation ( $1 \sigma$, dashed black line). Black bands show mineral inclusions in garnet.

The volume fractions used in this study are expressed as fractions of the entire system, i.e., the rock sample. Consequently the volume of garnet predicted by GRTMOD to be stable for stages $i>1$ must be corrected for the size of the subsystem being considered at each stage by the model (in Fig. 3, this corresponds to the blue, green, and red domains for stages 1,2 , and 3 , respectively).

\subsection{Objective function}

The objective function is composed of a loss function generating the number $L_{0}$ and a cost function generating the number $C_{0}$. Both parameters are used to quantify the amount by which the predicted garnet composition deviates from the measured values. The loss function is defined as:

$$
\begin{aligned}
& L_{0}\left(P^{i}, T^{i}, v^{i, j=1}, \ldots, v^{i, j=i}{ }^{1}\right) \\
& \quad=\sqrt{\sum_{k=1}^{m}\left(f_{k}^{\text {measured }}-f_{k}^{\text {model }}\right)^{2} \omega_{k},}
\end{aligned}
$$

where $f_{k}^{\text {measured }}$ and $f_{k}^{\text {modeled }}$ are the proportions of endmember $k$, as measured or modeled, and $\omega_{k}$ is the weighting factor of the corresponding element. The end-member
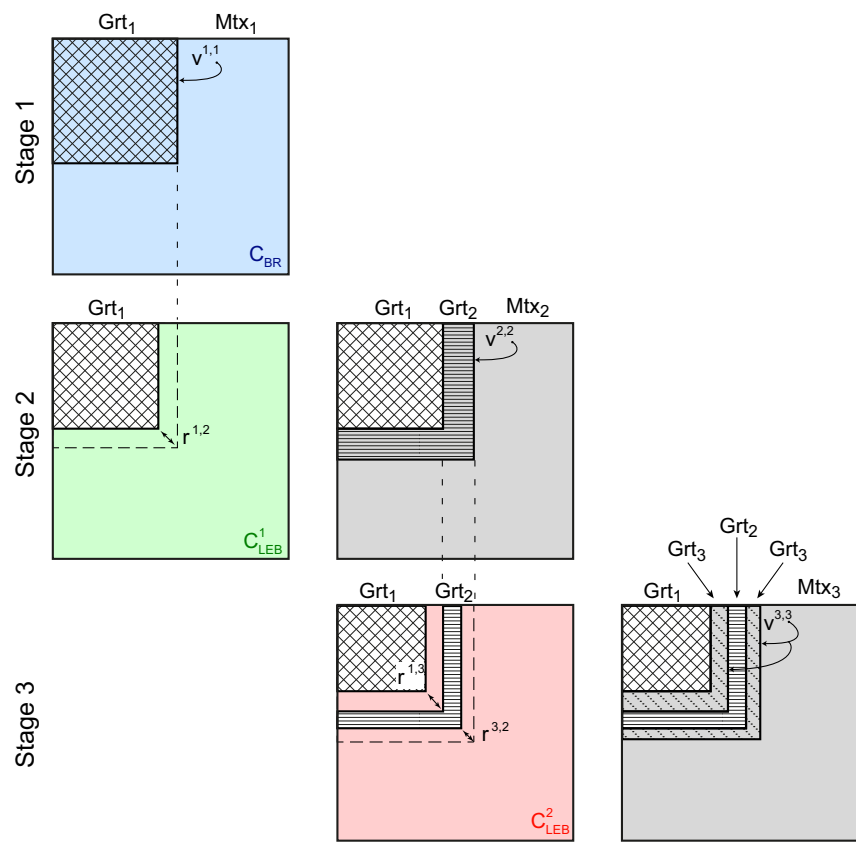

Fig. 3. Sketches illustrating garnet growth during three hypothetical stages that include resorption prior to growth stages 2 and 3. The colored domains are the subsystems being considered at each stage by the model. For stages 2 and 3, two sketches are displayed; the first one (left) shows the amount of resorption of previously formed garnet that is used to estimate the local effective bulk of that specific stage. The second sketch (right) shows the growth of a new garnet rim modeled using Gibbs free energy minimization. (Online version in color.)

proportions of grossular $\left(f_{\mathrm{Grs}}\right)$, pyrope $\left(f_{\mathrm{Prp}}\right)$, almandine $\left(f_{\mathrm{Alm}}\right)$, and spessartine $\left(f_{\mathrm{Sps}}\right)$ are calculated from $\mathrm{Ca}, \mathrm{Mg}, \mathrm{Fe}$, and $\mathrm{Mn}$ abundances, expressed in number of atoms per formula unit (apfu). However, the proportions $f_{\mathrm{Grs}}, f_{\mathrm{Prp}}, f_{\mathrm{Alm}}$ and $f_{\text {Sps }}$ are not known with the same precision, hence a weighting factor is required. It takes into account the relative analytical uncertainty of each end-member proportion by its variance $\sigma_{k}^{2}\left(\sigma_{k}\right.$ : standard deviation), hence the weighting factor is defined as

$\omega_{k}=\frac{1}{\sigma_{k}^{2}}$.

In mapping conditions, the precision $(1 \sigma)$ of the electron microprobe measurement of one pixel composition is estimated using a Poisson law (e.g., Lanari et al., 2014)

$p=\frac{1}{\sqrt{ } n}$,

where $n$ is the number of photons reaching the detector during a single measurement. The number of recorded counts $n$ is corrected for dead-time bias of the detector. For multiple independent measurements $f_{k}$ of the same X-ray flux $f$, the variance is close to

$\sigma_{k}^{2}=n$. 
This obvious relationship is derived from equation (9) and may be tested by calculating the variance of single measurements of the same composition. For a large set of measurements of a homogeneous material - such as a set of pixels of X-ray maps - the precision calculated from the variance matches the precision of the single-pixel estimate made using equation (9). By combining equations (8) and (10), it is possible to estimate the weighting factor of an end-member $k$ using the number of recorded counts $n_{k}$ of the corresponding element using the relationship

$$
\omega_{k}=\frac{1}{n_{k}} \text {. }
$$

Consequently, the loss function used in this study is

$$
\begin{aligned}
& L_{0}\left(P^{i},, \dot{T} j \bar{v}^{1}, \ldots,{ }^{i, j=i}{ }^{1}\right) \\
& =\sqrt{\sum_{k=1}^{m} \frac{\left(f^{\text {measured }}-f_{k}^{\text {model }}{ }^{₹}\right)}{n_{k}} .}
\end{aligned}
$$

The number $L_{0}$ generated by the loss function is minimized to derive the best set of variables (maximum likelihood solution). However, this number is not intuitively representing the deviation between model and measured compositions because of the weighting factor. This is the reason why a cost function is also part of the objective function. In contrast to the loss function, the cost function generates the number $C_{0}$, which is intuitively representing the quality of the solution. The cost function is defined as:

$$
\begin{aligned}
& \left.C_{0}\left(P^{i}, f^{i} \dot{v} 1\right), \ldots,{ }^{i, j=i}{ }^{1}\right) \\
& =\sqrt{\sum_{k=1}^{m}\left(f^{\text {measured }}-f_{k}^{\text {model }}{ }^{2},\right.}
\end{aligned}
$$

$C_{0}$ is the least square of the deviations between the model and measured end-member proportions without taking into account the uncertainty on the measurement. For garnet with four end-members, a value of $C_{0}<0.04$ indicates a good fit of the model. For garnet showing low Mn-content $(<1 \mathrm{wt} \%)$, only three end-members may be used to describe its composition. In such a case, a threshold value of 0.03 is set for $C_{0}$ (see application example below).

\subsection{Minimization procedure}

The problem addressed in this study is a nonlinear optimization problem for which the derivatives are not known. Consequently a heuristic search method has to be used; the Nelder-Mead technique (Nelder \& Mead, 1965), implemented in the MATLAB ${ }^{\odot}$ function fminsearch, was selected. It is critical for the user to understand the technique of minimization in order to evaluate the limits of this approach. A complete method description is available in Nelder \& Mead (1965) or when using the help function in MATLAB $^{\odot}$. This method uses the concept of simplex, a polytope of $n+1$ vertices in $n$ dimensions. The $n+1$ values of the objective function $L$ at the vertices are ordered and the position of the centroid is calculated of all $n$ points, except for the worst point $n+1$. Then the algorithm computes the values of the objective function at the reflected point, the expanded point and the contracted point of the worst point. If one of the previous values is smaller, the corresponding point replaces the worst point and the optimization continues, else a reduction step of the simplex is done. This procedure is repeated until convergence to a local minimum. The best solution found is a local minimum and may differ significantly from the global minimum of the objective function, which represents the maximum likeli-hood solution. Consequently the optimization must be done using different initial guesses. An attempt to provide an automated procedure is proposed in the next section. Advantages and disadvantages of this automated procedure are pointed out in the discussion.

\subsection{Toward an automated optimization strategy}

The optimization strategy depends on the number of variables being optimized. For instance, for the first stage $S^{1}$, only two variables $\left(P^{1}, T^{1}\right)$ are optimized, and the procedure is straightforward. For all subsequent stages $\left(S^{i}\right.$ $>{ }^{1}$ ), the problem is more complex because of the additional compositional variables (Fig. 3). The procedure is divided into three phases: optimization1, optimization2, and auto-refinement. During optimization 1, successive $P$ $T$ minimizations are carried out from different starting guesses in order to determine the global minimum within the $P-T$ window (Fig. 4a). Optimization 2 refines the garnet fraction variables $\left(\begin{array}{cc}v^{i, j} & 1 \rightarrow i^{i}\end{array}\right)$, as well as $P-T$ (Fig. 4b). The starting guess for optimization 2 is the best $P-T$ couple obtained during optimization1. A go fast mode is available to begin directly optimization 2 from user's favorite $P-T$ initial guess. Finally, the auto-refinement phase checks the local variability of the cost function $\left(C_{0}\right.$ value) in order to provide a relative uncertainty on the $P-T$ estimate (Fig. 5). A complete description of these three phases is presented in the Appendix 1.

\subsection{Compositional characterization of growth zones}

As discussed above, during a single growth stage the fractionation of the effective composition caused by garnet growth as well as small changes in $P$ and $T$ conditions are neglected. These two assumptions are critical and demand extensive characterization of the compositional variations of the studied sample. It is strongly recommended to use high-resolution quantitative compositional maps of garnet end-members to define the successive growth zones (see, e.g., areas used in Fig. 1). The quantitative X-ray mapping technique is useful to measure the compositional variability of metamorphic minerals at the thin-section scale (e.g., Lanari et al., 2012, 2013). Local compositional variations caused by surface crystal defects, late reequilibration with inclusions or fractures are not taken into account; any analyses showing mixed analyses close to the contact between two growth zones are discarded. In Fig. 2 , for 


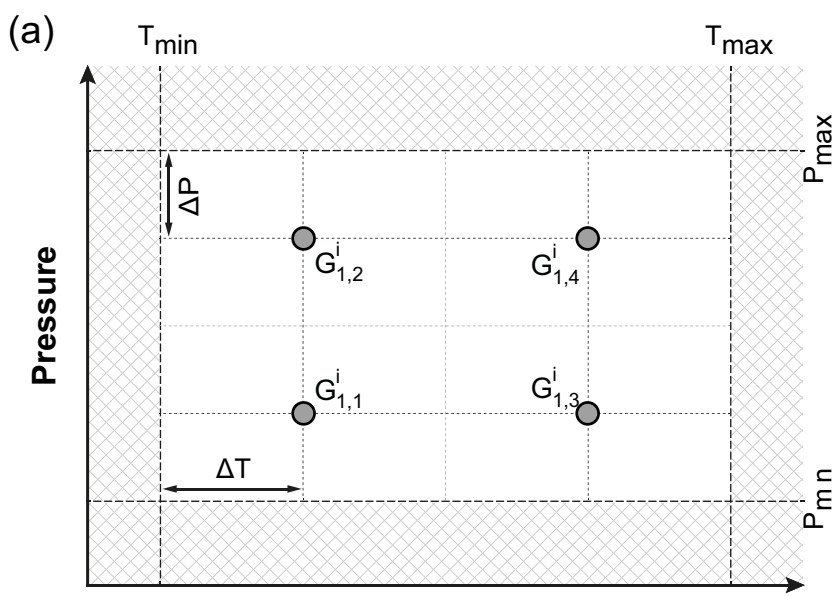

Temperature

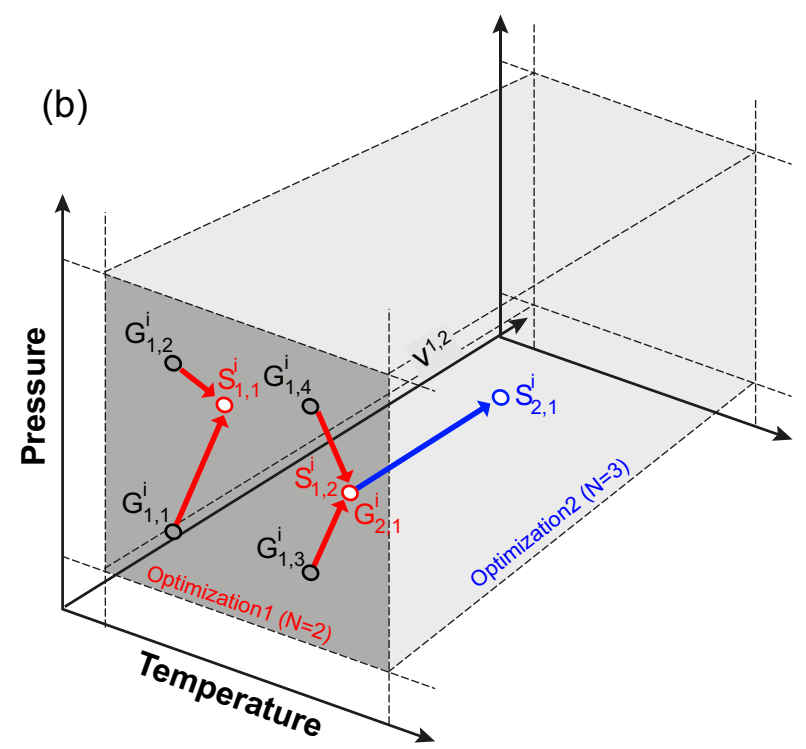

Fig. 4. Sketches illustrating the automated procedure. (a) Pressure temperature diagram within $T_{\min } T_{\max }, P_{\min } P_{\max }$. The $G_{1, r}^{i}$ are the four initial guesses $(r \quad 1: 4)$. (b) Pressure $(P)$ temperature $(T)$ composition $(X)$ diagram describing the two stage optimization. Optimization1 is carried out in $P T$ space (red), optimization2 in $P$ $T v$ space (blue). In this example $C_{0}$ of $S_{1,2}^{i}$ is smaller than $C_{0}$ of $S_{1,1}^{i}$ and is selected as the best $P$ T couple obtained during optimization1. (Online version in color.)

example, the intermediate compositions between the defined growth stages are not being considered. It is not excluded that they may result from protracted growth with a minor change in $P-T$ conditions or kinetic-controlled growth. This approach critically relies on the chemical information stored in the natural sample and, therefore, on the quality of the microprobe measurements. No a priori assumption is made on the $P-T$ conditions of each stage. However, some garnet compositions from some growth stages may have been totally resorbed during later stages. If the composition is not preserved in the present-day specimen, it is obvious that $P-T$ conditions cannot be retrieved using this approach.

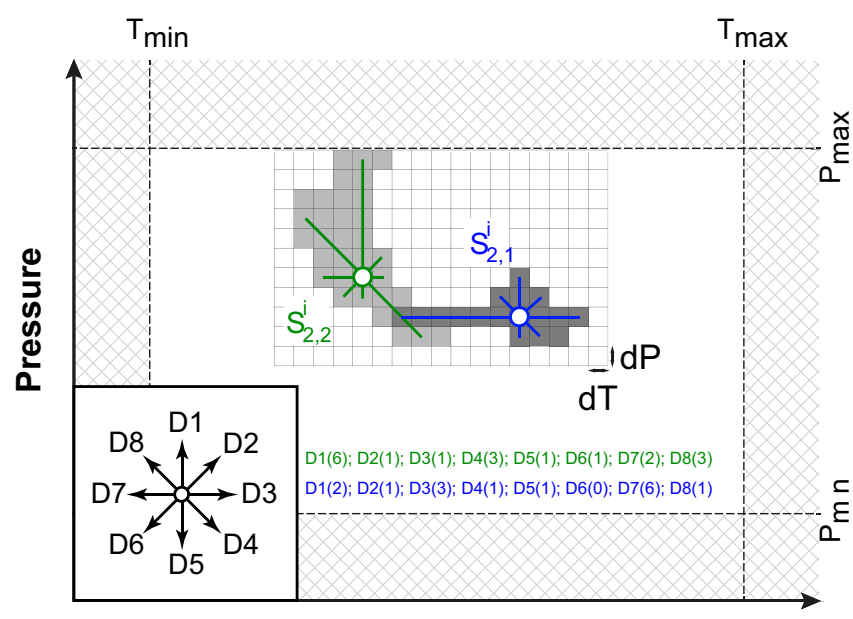

Temperature

Fig. 5. Sketch illustrating the refinement procedure, which checks the local variability of the cost function. Two hypothetic solutions 1 and 2 are found for stage i. $D 1(n 1), D 2(n 2), \ldots, \mathrm{D} 8(n 8)$ give the directions $(D)$ and the number of steps calculated along them $(n) . \mathrm{d} P$ and $\mathrm{d} T$ are the $P$ and $T$ increments. The gray areas correspond to domains with $C_{0}<T C_{0}$. For a given direction $D$, the refinement stops if $C_{0}>T C_{0}$. (Online version in color.)

\section{Benchmarking test for a sample showing typical prograde garnet zoning}

To benchmark GrTMod, $P-T$ conditions of a garnet in the San Emigdio Schist (sample 06SE23 from Chapman et al., 2011) were estimated in a system simplified to $\mathrm{SiO}_{2^{-}}$ $\mathrm{Al}_{2} \mathrm{O}_{3}-\mathrm{FeO}-\mathrm{MnO}-\mathrm{MgO}-\mathrm{CaO}-\mathrm{Na}_{2} \mathrm{O}-\mathrm{K}_{2} \mathrm{O}-\mathrm{H}_{2} \mathrm{O}$ using the same thermodynamic dataset (TC321p2.txt) and $C_{\mathrm{BR}}$ as in that study. This example was selected because (i) the authors demonstrated that the effects of intracrystalline diffusion were limited to narrow zones $(\sim 10 \mu \mathrm{m}$; Fig. 7 in Chapman et al., 2011), and (ii) there is no clear evidence of resorption (see Fig. 6a,b in Chapman et al., 2011). Thus the automated optimization strategy of GRTMOD is expected to predict incremental growth of garnet along the prograde $P-T$ history without resorption.

The zoning profile reported in Fig. 5b of Chapman et al. (2011) was divided into four successive growth zones: $\mathrm{Grt}_{1}$ (0.37 vol\%, $\left.\mathrm{Alm}_{36} \mathrm{Prp}_{2} \mathrm{Grs}_{26} \mathrm{Sps}_{36}\right) ; \mathrm{Grt}_{2} \quad(0.12 \mathrm{vol} \%$, $\mathrm{Alm}_{57} \operatorname{Prp}_{3} \mathrm{Grs}_{33} \mathrm{Sps}_{7}$ ); $\mathrm{Grt}_{3}$ (4.2 vol\%, $\mathrm{Alm}_{67} \operatorname{Prp}_{7} \mathrm{Grs}_{25} \mathrm{Sps}_{1}$ ); and $\mathrm{Grt}_{4}$ (2.31 vol\%, $\left.\mathrm{Alm}_{64} \mathrm{Prp}_{9} \mathrm{Grs}_{26} \mathrm{Sps}_{1}\right)$. The volume fraction of each growth zone was calculated assuming a total of $7 \mathrm{vol} \%$ of garnet being produced during the prograde $P-T$ history (value taken from Fig. 11b of Chapman et al., 2011). As explained above (see Sect. 2), the procedure requires a subdivision into discrete stages of growth, and four stages where selected based on the zoning profile.

The benchmark results are reported in Fig. 6. The model predicts that garnet grows along a prograde trajectory with increasing $T$ and $P$ from $\sim 450{ }^{\circ} \mathrm{C}$ to $\sim 630^{\circ} \mathrm{C}$ and $4 \mathrm{kbar}$ to $11 \mathrm{kbar}$. It is important to point out here that the model does not predict any resorption of the previous growth zones (Fig. 6b), in line with the 
(a)

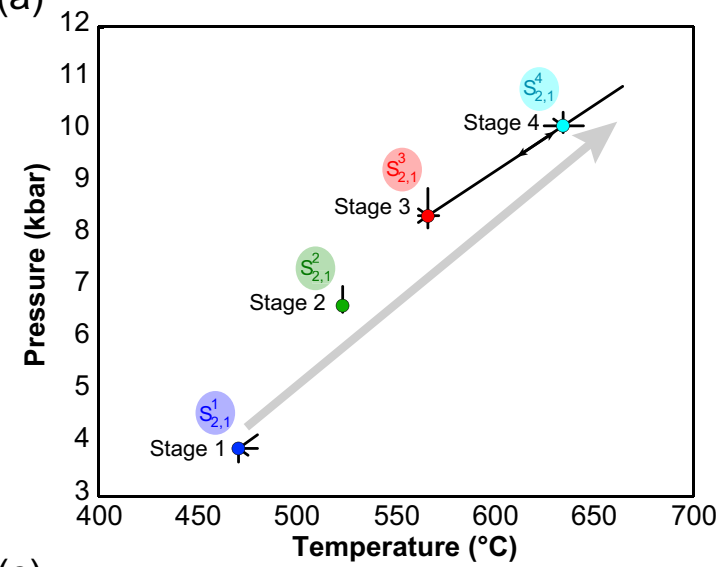

(c)

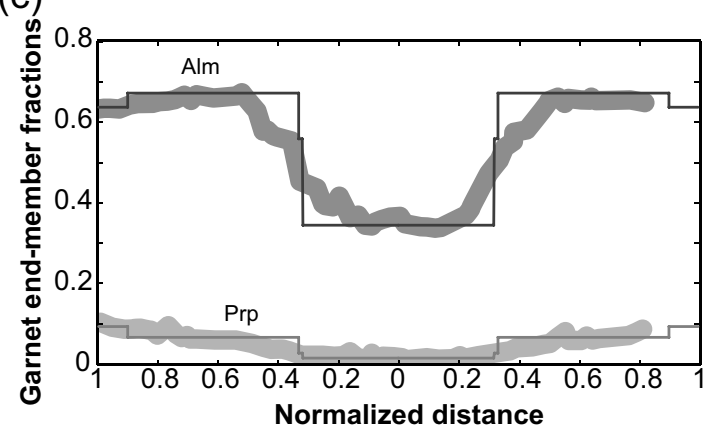

(b)
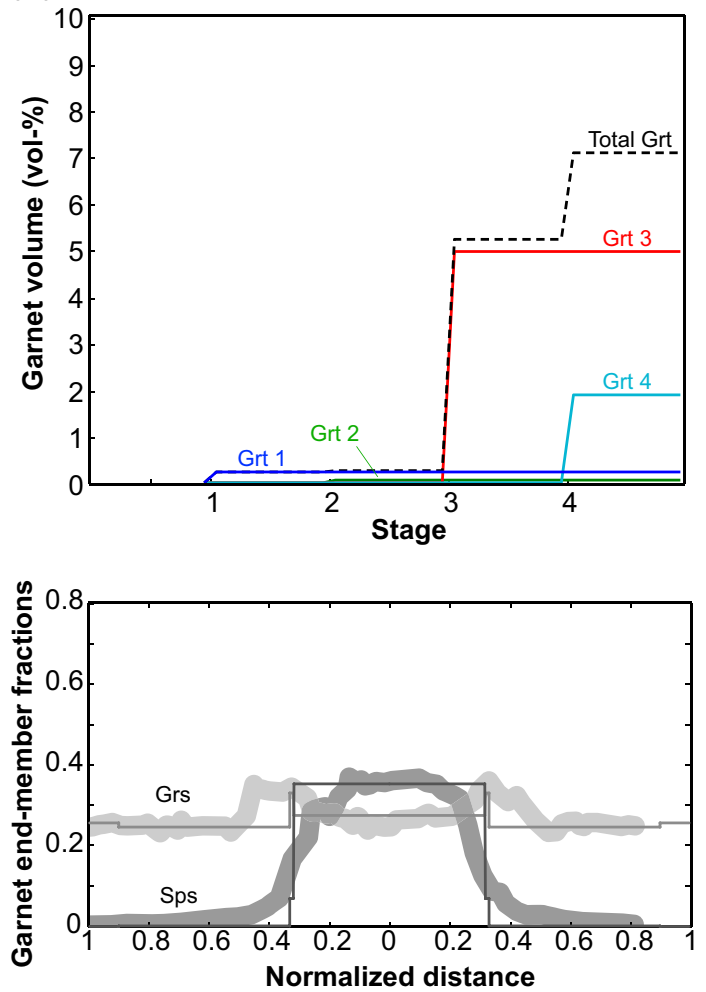

Fig. 6. Results of the benchmark test (see text for details). (a) $P T$ diagram with the solutions obtained for the four stages; best solutions are highlighted. Reported in gray is the $P T$ path obtained by Chapman et al. (2011). (b) Volume fraction of garnet predicted by the best model for stages 1, 2, 3, and 4. (c) Zoning profiles (thick lines) and predictions from this study (thin) for almandine and pyrope (left); grossular and spessartine (right). (Online version in color.)

conclusions of Chapman et al. (2011), and the model results were obtained without any intervention from the user. The predicted zoning profiles are compared with the measured one in Fig. 6c,d. Although Grt2 is slightly underestimated in the model $(0.03 \mathrm{vol} \%$ instead of 0.12 vol\%), the predicted profile shape perfectly matches the observations. The residuals are very low $\left(C_{0}\right.$ between 0.007 and 0.025 ) resulting in an excellent match of the modeled compositions.

\section{Sample description and compositional mapping}

The studied sample FG12-157 is an eclogitic garnetbearing micaschist from the Sesia Zone in the Italian Western Alps (see Supplementary Material S6 for photographs). It was selected from a collection of $\sim 10$ samples showing similar garnet resorption features because it illustrates well the strengths and weaknesses of the automated approach. Other samples, some of which show more $P-T$ stages or no resorption (Giuntoli, 2016), will be presented in a subsequent study. Sample FG12-157 was collected at Lillianes in the Lys Valley in Italy ( $X=$ 409683; $Y=5054033$ ED 1950 UTM Zone 32N). This micaschist is made of quartz (40 vol\%), phengite
(30 vol\%), garnet $(15 \mathrm{vol} \%$,) glaucophane (6vol\%), and epidote (4 vol\%), with minor chlorite, albite, rutile, zircon, titanite, ilmenite, and graphite (all together of about $5 \mathrm{vol} \%$ ). A strong eclogitic foliation is marked by phengite, glaucophane and allanite; it was subsequently deformed into open folds. Garnet-grain size ranges from $200 \mu \mathrm{m}$ up to several $\mathrm{mm}$. Microscopically, large garnet porphyroblasts systematically show a bright core surrounded by a dark rim. The small grains, however, are dark crystals with features similar to the rims of porphyroblasts. The cloudy appearance of the dark garnet is mostly due to fine rutile inclusions. Glaucophane and phengite inclusions are frequent in the dark rim, whereas only quartz is found in the bright core. In the matrix, glaucophane shows characteristic core to rim zoning, with more strongly pleochroic rims (darker blue compared to core) reflecting higher iron contents. Some glaucophane grains are rimmed by green amphibole, indicating local and limited retrogression, with minor chlorite and albite reflecting greenschist-facies conditions. Allanite shows REE-rich cores and locally a clinozoisite rim $(10 \mu \mathrm{m})$. Other accessories are graphite, zircon, and rutile overgrown by titanite and followed by an ilmenite rim.

Electron probe microanalyses (EPMA) were performed using a JEOL JXA-8200 superprobe at the Institute of Geological Sciences (University of Bern). Following the 
Table 2. Average compositions and standard deviation of garnet.

\begin{tabular}{|c|c|c|c|c|c|c|c|c|}
\hline \multirow[b]{2}{*}{$\ldots$} & \multicolumn{2}{|c|}{ Core $\left(\mathrm{Grt}_{1}\right)\left(\begin{array}{ll}n & 920\end{array}\right)$} & \multicolumn{2}{|c|}{ Fractures $\left(\begin{array}{ll}n & 22\end{array}\right)$} & \multicolumn{2}{|c|}{$\operatorname{Rim1}\left(\mathrm{Grt}_{2}\right)(n$ 964) } & \multicolumn{2}{|c|}{$\operatorname{Rim} 2\left(\mathrm{Grt}_{3}\right)\left(\begin{array}{ll}n & 319\end{array}\right)$} \\
\hline & Average & St. Dev. & Average & St. Dev. & Average & St. Dev. & Average & St. Dev. \\
\hline $\mathrm{SiO}_{2}$ & 38.17 & 0.54 & 37.83 & 1.38 & 38.28 & 1.21 & 38.73 & 1.52 \\
\hline $\mathrm{TiO}_{2}$ & 0.07 & 0.01 & 0.07 & 0.01 & 0.25 & 0.59 & 0.2 & 0.64 \\
\hline $\mathrm{Al}_{2} \mathrm{O}_{3}$ & 21.07 & 0.34 & 21.10 & 0.36 & 21.04 & 0.71 & 21.35 & 0.89 \\
\hline $\mathrm{FeO}$ & 31.25 & 0.61 & 30.94 & 0.69 & 28.87 & 1.01 & 26.61 & 1.36 \\
\hline $\mathrm{MnO}$ & 0.99 & 0.28 & 0.74 & 0.18 & 0.51 & 0.16 & 0.37 & 0.14 \\
\hline $\mathrm{MgO}$ & 6.42 & 0.19 & 4.94 & 0.45 & 4.89 & 0.29 & 3.78 & 0.35 \\
\hline $\mathrm{CaO}$ & 1.36 & 0.16 & 4.15 & 0.64 & 5.67 & 0.28 & 9.12 & 0.7 \\
\hline $\mathrm{Na}_{2} \mathrm{O}$ & 0.05 & 0.02 & 0.05 & 0.02 & 0.06 & 0.02 & 0.05 & 0.04 \\
\hline $\mathrm{K}_{2} \mathrm{O}$ & 0.01 & $<0.01$ & 0.01 & $<0.01$ & 0.01 & $<0.01$ & 0.01 & $<0.01$ \\
\hline \multicolumn{9}{|c|}{ Structural formula (12 anhydrous oxygen basis) } \\
\hline $\mathrm{Si}$ & 3.02 & 0.03 & 3.00 & 0.06 & 3.03 & 0.06 & 3.03 & 0.07 \\
\hline $\mathrm{Al}$ & 1.97 & 0.03 & 1.97 & 0.05 & 1.96 & 0.06 & 1.97 & 0.08 \\
\hline $\mathrm{Mg}$ & 0.76 & 0.02 & 0.58 & 0.05 & 0.58 & 0.03 & 0.44 & 0.04 \\
\hline $\mathrm{Fe}$ & 2.07 & 0.04 & 2.05 & 0.06 & 1.91 & 0.07 & 1.74 & 0.09 \\
\hline $\mathrm{Mn}$ & 0.01 & $<0.01$ & 0.01 & $<0.01$ & 0.01 & $<0.01$ & 0.01 & 0.01 \\
\hline $\mathrm{Ca}$ & 0.12 & 0.01 & 0.35 & 0.05 & 0.48 & 0.02 & 0.77 & 0.06 \\
\hline $\mathrm{X}_{\mathrm{Alm}}$ & 0.69 & 0.01 & 0.68 & 0.02 & 0.64 & 0.01 & 0.59 & 0.02 \\
\hline $\mathrm{X}_{\text {Gro }}$ & 0.04 & 0.01 & 0.12 & 0.02 & 0.16 & 0.01 & 0.26 & 0.02 \\
\hline $\mathrm{X}_{\mathrm{Pyr}}$ & 0.25 & 0.01 & 0.19 & 0.02 & 0.19 & 0.01 & 0.15 & 0.01 \\
\hline $\mathrm{X}_{\mathrm{Sps}}$ & 0.02 & 0.01 & 0.02 & $<0.01$ & 0.01 & $<0.01$ & 0.01 & $<0.01$ \\
\hline \multicolumn{9}{|c|}{ GRTMOD input values } \\
\hline $\mathrm{F}_{\mathrm{Alm}}$ & 0.703 & & & & 0.644 & & 0.591 & \\
\hline $\mathrm{W}_{\mathrm{alm}}$ & 3750 & & & & 3280 & & 3000 & \\
\hline$f_{\text {Grs }}$ & 0.039 & & & & 0.162 & & 0.259 & \\
\hline $\mathrm{W}_{\mathrm{Grs}}$ & 420 & & & & 1820 & & 2920 & \\
\hline$f_{\text {Prp }}$ & 0.258 & & & & 0.194 & & 0.15 & \\
\hline $\mathrm{W}_{\operatorname{Prp}}$ & 1270 & & & & 980 & & 720 & \\
\hline
\end{tabular}

procedure described in Lanari et al. (2013, 2014), the EPMA session is divided into two steps, i.e., the measurement of point analyses and X-ray compositional maps, both in wavelength-dispersive mode (WDS). Analytical conditions for point analyses were $15 \mathrm{kV}$ accelerating voltage, $20 \mathrm{nA}$ specimen current, and $40 \mathrm{~s}$ dwell time (including $2 \times 10 \mathrm{~s}$ of background measurement). Nine oxide components were measured, using synthetic and natural standards: wollas-tonite $\left(\mathrm{SiO}_{2}\right)$, anorthite $\left(\mathrm{Al}_{2} \mathrm{O}_{3}, \mathrm{CaO}\right)$, almandine $(\mathrm{FeO})$, spinel $(\mathrm{MgO})$, orthoclase $\left(\mathrm{K}_{2} \mathrm{O}\right)$, albite $\left(\mathrm{Na}_{2} \mathrm{O}\right)$, ilmenite $\left(\mathrm{TiO}_{2}\right)$, and tephroite $(\mathrm{MnO})$. Analytical conditions for X-ray maps were $15 \mathrm{kV}$ accelerating voltage, $100 \mathrm{nA}$ specimen current, and a dwell time of $200 \mathrm{~ms} /$ pixel. Nine elements ( $\mathrm{Si}, \mathrm{Ti}, \mathrm{Al}, \mathrm{Fe}, \mathrm{Mn}, \mathrm{Mg}, \mathrm{Na}, \mathrm{Ca}$ and $\mathrm{K}$ ) were measured at the specific wavelength in two passes. Intensity maps were standardized using spot analyses as internal standard. X-ray maps were processed using XMapTools 2.2.1 (Lanari et al., 2014). The average composition of each growth zone was calculated from the map pixels selected (Fig. 1). Analytical uncertainties (derived using Eq. (9)) were propagated through the structural formulae computation using a Monte-Carlo simulation. Compositional data and corresponding ana-lytical uncertainties are reported in Table 2. The sum of the analytical uncertainties on $f_{\operatorname{Prp}}, f_{\text {Grs }}$ and $f_{\text {Alm }}$ is about 0.03 . This value is used to define the value of STOL.

\section{Results}

\subsection{Garnet composition and texture}

Garnet exhibits complex zoning as shown by compositional maps of end-member proportions (Fig. 1). The cores are Prp- and Alm-rich and Grs-poor $\left(\mathrm{Alm}_{68-70} \operatorname{Prp}_{24-26} \mathrm{Grs}_{3-5} \mathrm{Sps}_{1-3}\right.$, Table 2). Cores have lobate edges suggesting resorption. A new garnet enriched in Grs and depleted in Prp and Alm $\left(\mathrm{Alm}_{66-70} \operatorname{Prp}_{17-21} \mathrm{Grs}_{10-14} \mathrm{Sps}_{1-3}\right)$ fills up numerous fractures (Fig. 1). Two distinct over-growths surround the apparently porphyroclastic cores: a first rim $\left(\mathrm{Alm}_{63-65} \operatorname{Prp}_{18-20} \mathrm{Grs}_{15-17} \mathrm{Sps}_{1}\right)$ and a second rim $\left(\mathrm{Alm}_{57-61} \operatorname{Prp}_{14-16} \mathrm{Grs}_{24-28} \mathrm{Sps}_{1}\right)$ (Fig. 1e). Sample textures indicate that the second rim grew on internally and externally resorbed portions of the first rim, i.e., the second rim is observed directly surrounding the core as well as the first rim. This observation suggests that partial resorption of garnet core plus growth of the first rim may have occurred before or during growth of the second rim (third stage in Fig. 3). The first rim is identical in composition to garnet that seals hairline fractures in the core. This observation supports the sequence of crystallization proposed here. Resorption of garnet core is common in polymetamorphic rocks, sometimes leading to the formation of mushroom-shaped and atoll garnet 
(Robyr et al., 2014 and references therein). Based on these textural and compositional relationships, three growth stages are defined: stage 1 corresponding to the growth of garnet core $\left(\mathrm{Grt}_{1}\right)$, stage 2 for the first rim $\left(\mathrm{Grt}_{2}\right)$, and stage 3 for the second rim $\left(\mathrm{Grt}_{3}\right)$.

\subsection{Thermodynamic models}

For this application example, the thermodynamic dataset of Berman (1988) with subsequent updates collected in JUN92.bs (distributed with Theriak-Domino 03.01.2012) was used together with the following solution models: Berman (1990) for garnet; Fuhrman and Lindsley (1988) for feldspar; Meyre et al. (1997) for omphacite; Keller et al. (2005) for white mica, and ideal mixing models for amphibole (Mäder \& Berman, 1992; Mäder et al., 1994), epidote and chlorite (Hunziker, 2003). As the studied garnet contains $<1 \mathrm{wt} \% \mathrm{MnO}$, restricted to parts of the core (suggesting heterogeneous distribution of the Mnrich precursors), the $\mathrm{Mn}$ compo-nent is ignored and the system simplified to $\mathrm{SiO}_{2}-\mathrm{TiO}_{2}-\mathrm{Al}_{2} \mathrm{O}_{3}-\mathrm{FeO}-\mathrm{MgO}-\mathrm{CaO}-$ $\mathrm{Na}_{2} \mathrm{O}-\mathrm{K}_{2} \mathrm{O}-\mathrm{H}_{2} \mathrm{O}$. For other cases, where Mn-rich garnet is modeled, the $\mathrm{MnO}$ component must be added to the system (e.g., benchmark test in Sect. 3). The anhydrous $C_{\mathrm{BR}}$, determined by XRF, comprises $\mathrm{SiO}_{2}(60.36 \mathrm{wt} \%)$, $\mathrm{TiO}_{2}(1.03 \mathrm{wt} \%), \mathrm{Al}_{2} \mathrm{O}_{3}(16.51 \mathrm{wt} \%), \mathrm{FeO}$ (7.95 wt $\left.\%\right)$, $\mathrm{MgO}$ (3.29 wt\%), $\mathrm{CaO}$ (2.09 wt\%), $\mathrm{Na}_{2} \mathrm{O}$ (1.19 wt\%), and $\mathrm{K}_{2} \mathrm{O}(3.57 \mathrm{wt} \%)$. Because of the lack of experimental data and suitable ferric end-members in solid-solution models, $\mathrm{Fe}^{3+}$ was ignored. All Gibbs free energy minimizations were carried out assuming a saturating pure $\mathrm{H}_{2} \mathrm{O}$ fluid. The amount of $\mathrm{H}_{2} \mathrm{O}$ predicted at high $P$ is in line with the measured LOI $(2.01 \mathrm{wt} \%)$ in the present-day sample. End-member mineral abbreviations used throughout text and figures are from Whitney \& Evans (2010).

The model is restricted to a $P-T$ window between 500 $900{ }^{\circ} \mathrm{C}$ and $5-20 \mathrm{kbar}$. Minimum garnet abundances, i.e., those preserved in the present-day sample, were fixed at 4 vol $\%$ for $\mathrm{Grt}_{1}, 3$ vol\% for $\mathrm{Grt}_{2}$, and 4 vol\% for $\mathrm{Grt}_{3}$. Details regarding the results printed out by GRTMOD and the modeled assemblages are reported in Supplementary Material S1-S5 (linked to this article and freely available online at the GSW website of the journal: http://eurjmin. geoscienceworld.org), corresponding to the stages described in the following subsections. Input and output values of selected variables are reported in Table 4.

\subsubsection{Stage 1}

During stage 1, only $P^{1}$ and $T^{1}$ are optimized. Four starting guesses $G_{1,1}^{1}, G_{1,2}^{1}, G_{1,3}^{1}, G_{1,4}^{1}$ were defined at $600^{\circ} \mathrm{C}-8 \mathrm{kbar}$, $600{ }^{\circ} \mathrm{C}-16 \mathrm{kbar}, 800{ }^{\circ} \mathrm{C}-8 \mathrm{kbar}$, and $800{ }^{\circ} \mathrm{C}-16 \mathrm{kbar}$, respec-tively, following the procedure described in Fig. 4. It is instructive to follow the iterations step by step and to describe the results provided in Table 3.

The first minimization $\left(G_{1,1}^{1}\right.$ from $\left.600^{\circ} \mathrm{C}-8 \mathrm{kbar}\right)$ converges to a minimum at $851^{\circ} \mathrm{C}$ and $6.03 \mathrm{kbar}$ for a $C_{0}$ value of 0.021 . A solution $S_{1,1}^{1}$ is retained for the following because for this first minimization $C_{0}<0.03$. Model $f_{\text {Alm }}$ and $f_{\text {Grs }}$ differ from the measured values by $\sim 0.01$ each. $10.5 \mathrm{vol} \%$ of garnet is predicted to be stable at that stage. The second minimization $\left(G_{1.2}^{1}\right.$ from $600{ }^{\circ} \mathrm{C}-$ $16 \mathrm{kbar}$ ) converges to a different minimum at $674^{\circ} \mathrm{C}$ and $17.49 \mathrm{kbar}$ with a $C_{0}$ value of 0.107 . As $C_{0}$ is much higher, model $f_{\mathrm{Alm}}$ and $f_{\text {Grs }}$ are quite different from the measured values (model, 0.62 and 0.11 ; measured, 0.70 and 0.04 ) and no solution is saved because $C_{0}>0.03$. The third minimization $\left(G_{1,3}^{1}\right.$ from $800^{\circ} \mathrm{C}-8 \mathrm{kbar}$ ) converges to a minimum at $851^{\circ} \mathrm{C}$ and $6.02 \mathrm{kbar}$ for a $C_{0}$ value of 0.021 . This result is fairly similar to solution $S_{1,1}^{1}$, indeed minimizations 1 and 3 converge to the same local minimum. The fourth minimization $\left(G_{1.4}^{1}\right.$ from $800^{\circ} \mathrm{C}-$ $16 \mathrm{kbar}$ ) converges to a minimum at $899^{\circ} \mathrm{C}$ and $6.14 \mathrm{kbar}$ for a $C_{0}$ value of 0.015 . A solution $S_{1,2}^{1}$ is obtained $\left(C_{0}<0.03\right) .7 .14 \mathrm{vol} \%$ of garnet is predicted to be stable at that stage. The second solution $\left(S_{1,2}^{1}\right)$ has a smaller value of $C_{0}\left(\mathrm{Co}_{1,2}^{1}<C o_{1,1}^{1}\right)$ and is selected as the best solution for stage 1: $S_{\text {best }}^{1}=S_{1,2}^{1}$ (see Fig. 7; Tables 3 and 4).

\subsubsection{Stage 2 - automated procedure}

For stage 2, the optimization is divided into two steps: optimization1 and optimization2. During optimization1, a fixed amount of garnet $\mathrm{Grt}_{1}(7.14 \mathrm{vol} \%)$, corresponding to the amount predicted during stage 1 , is initially fractionated from the $C_{\mathrm{BR}}$. The $P-T$ conditions of the four starting guesses $G_{1,1}^{2}, G_{1,2}^{2}, G_{1,3}^{2}, G_{1,4}^{2}$ are the same as for stage 1 (see above). The first minimization $\left(G_{1,1}^{2}\right.$ from $600{ }^{\circ} \mathrm{C}-8 \mathrm{kbar}$ ) converges to a minimum at $719^{\circ} \mathrm{C}$ and

$9.66 \mathrm{kbar}$ with $C_{0}=1.74 \times 10^{4}$. A temporary solution $S_{1,1}^{2}$ is stored; $5.95 \mathrm{vol} \%$ of garnet is predicted to be stable at that stage. The second minimization $\left(G_{1,2}^{2}\right.$ from $600{ }^{\circ} \mathrm{C}-$ $16 \mathrm{kbar}$ ) converges to a minimum at $647^{\circ} \mathrm{C}$ and $16.03 \mathrm{kbar}$ with $C_{0}=4.15 \times 10^{3}$. A temporary solution $S_{1,2}^{2}$ is stored; $9.02 \mathrm{vol} \%$ of garnet is predicted to be stable at that stage.

The third minimization $\left(G_{1,3}^{2}\right.$ from $\left.800{ }^{\circ} \mathrm{C}-8 \mathrm{kbar}\right)$ converges to a solution $S_{1,3}^{2}$ at $719^{\circ} \mathrm{C}$ and $9.66 \mathrm{kbar}$ with $C_{0}=1.25 \times 10^{4}$. This solution is close to $S_{1,2}^{2}$ with a slightly smaller residual. The fourth minimization $\left(G_{1,4}^{2}\right.$ from $800^{\circ} \mathrm{C}-16 \mathrm{kbar}$ ) converges to a solution $S_{1,4}^{2}$ similar to $S_{1,2}^{2}$. Optimization1 of stage 2 shows that for the same $C_{\mathrm{BR}}$ (i.e., without resorption) $\mathrm{Grt}_{2}$ is predicted stable at $719^{\circ} \mathrm{C}$ and $9.66 \mathrm{kbar}$ and $647^{\circ} \mathrm{C}$ and $16.03 \mathrm{kbar}$. The automated algorithm selects $S_{1,3}^{2}$ as the best solution based on the $C_{0}$ values $\left(S_{1, \text { best }}^{2}=S_{1,3}^{2}\right)$.

The $P-T$ conditions of initial guesses of optimization2 are fixed at $719{ }^{\circ} \mathrm{C}$ and $9.66 \mathrm{kbar}$. A new variable $v^{2,1}$ corresponding to the quantity of garnet $\mathrm{Grt}_{1}$ crystallized during stage 1 and fractionated from the bulk composition during stage 2 is introduced in the variable list of the objective function. Three starting guesses are defined assuming no resorption $\left(v^{2,1}=7.14 \mathrm{vol} \%\right)$, strong resorption $\left(v^{2,1}=4 \mathrm{vol} \%\right)$ and moderate resorption $\left(v^{2,1}=5.57\right.$ vol\%). The garnet volume fraction used as input for the second starting guess corresponds to the amount of garnet that is preserved in the present-day sample. The first minimization $\left(G_{2,1}^{2}\right.$ of $\left.7.14 \mathrm{vol} \%\right)$ converges to a 
Table 3. Detailed results from GrTMoD.

Stage 1

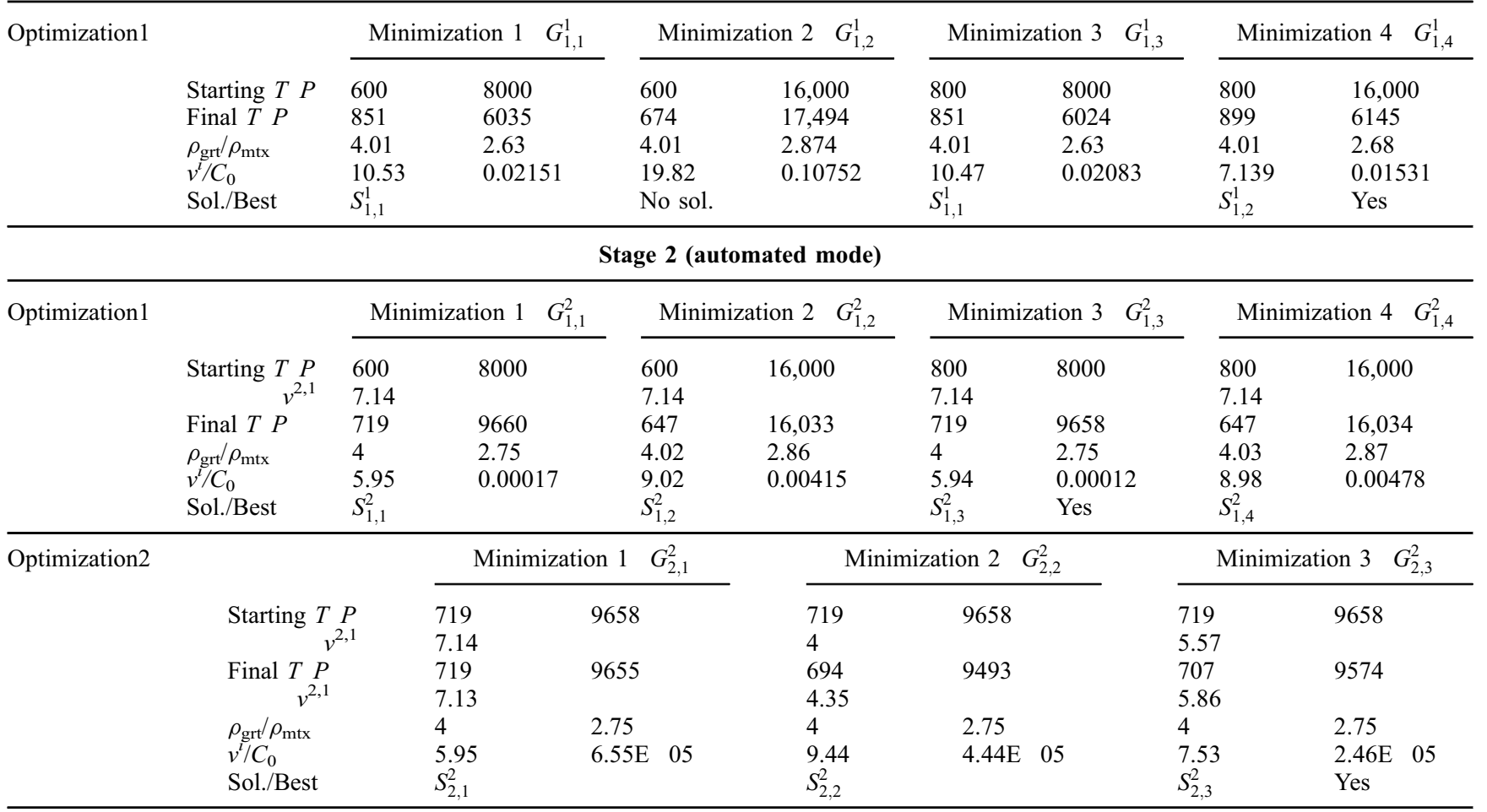

Stage 2 (go fast mode)

Optimization2

\begin{tabular}{llll} 
& Minimization 1 & $G_{2,1}^{2}$ & \\
\hline 650 & & 16,000 & \\
5.57 & & & \\
647 & & 15,947 & \\
5.92 & & & \\
4.02 & 2.86 & \\
10.40 & $8.12 \mathrm{E} \quad 06$ \\
$S_{2,1}^{2}$ & Yes & \\
\hline
\end{tabular}

Stage 3 (automated mode)

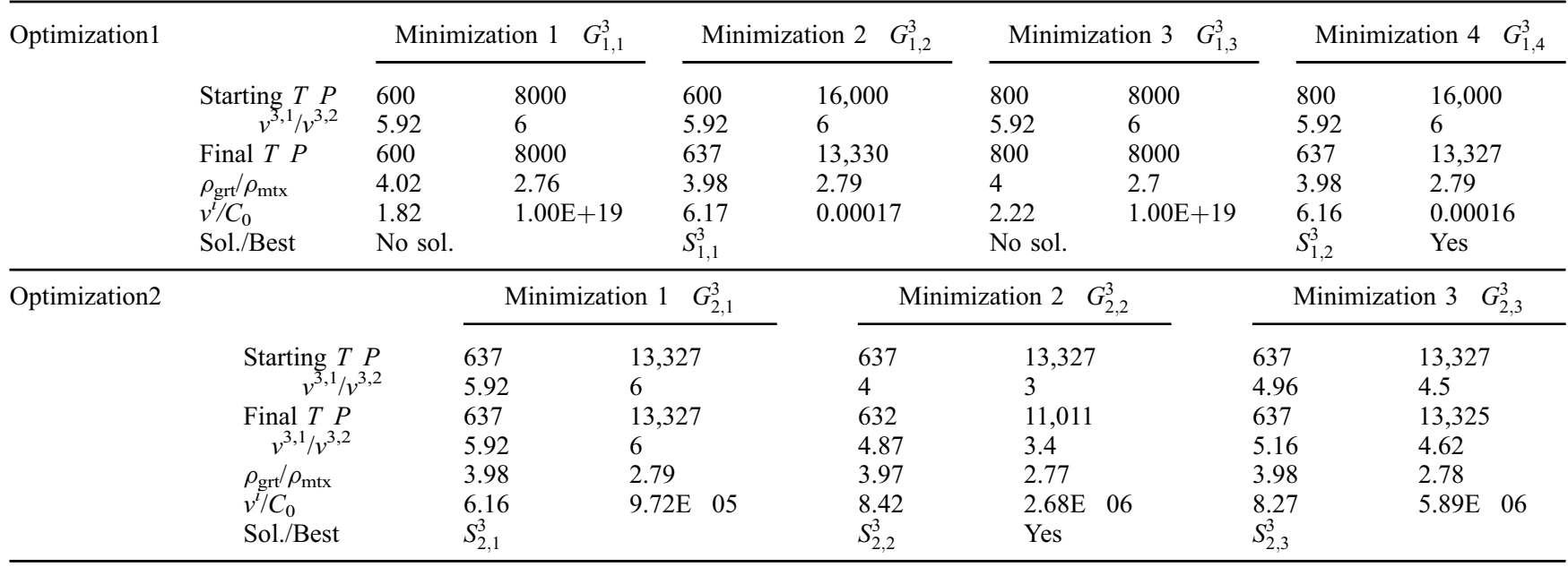



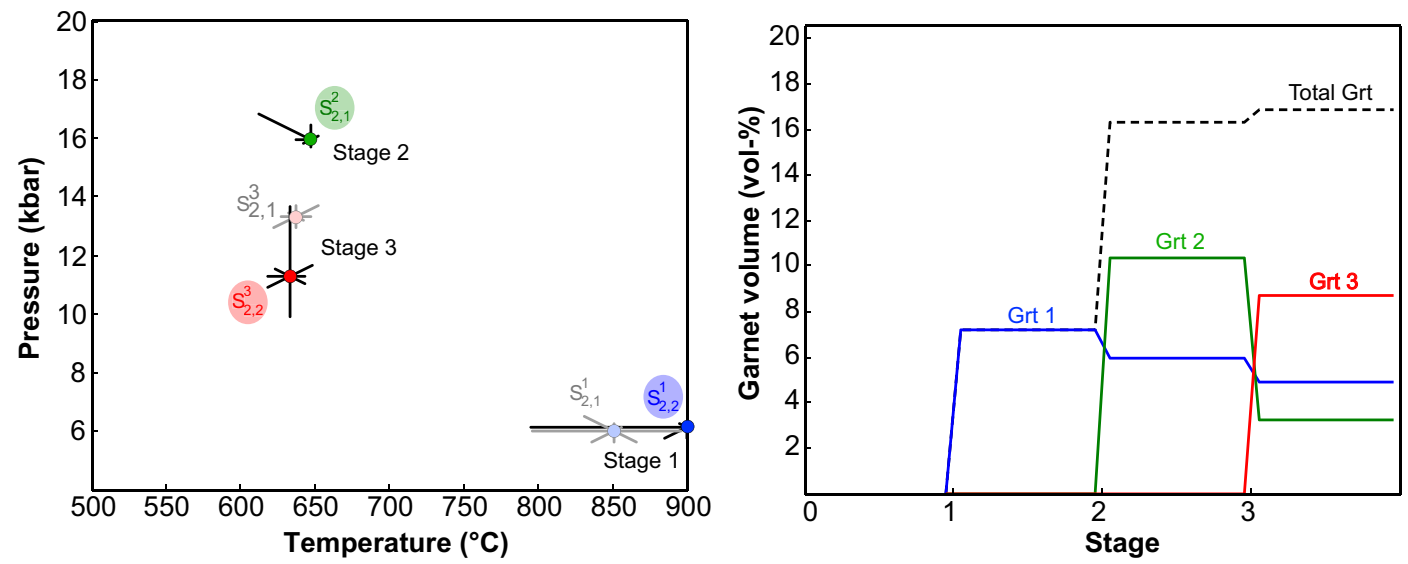

Fig. 7. Results for the application example (eclogitic micaschist from the Sesia Zone). (a) $P T$ diagram where all the solutions for the three stages are reported. The best solutions (see text) are highlighted. Note that the alternative solutions for stages 1 and 3 (not used in this model) are reported in gray. (b) Volume fraction of garnet predicted by the best model during stages 1, 2 and 3. (Online version in color.)

Table 4. Final model results.

\begin{tabular}{|c|c|c|c|c|}
\hline & $\mathrm{Grt}_{1}$ & $\mathrm{Grt}_{2}$ & $\mathrm{Grt}_{3}$ & Total \\
\hline \multicolumn{5}{|c|}{ Garnet resorption (vol\%) } \\
\hline Stage 1 & 0 & 0 & 0 & 0 \\
\hline Stage 2 & 1.215 & 0 & 0 & 1.215 \\
\hline Stage 3 & 1.059 & 7 & 0 & 8.059 \\
\hline \multicolumn{5}{|c|}{ Volume of garnet (vol\%) } \\
\hline Stage 1 & 7.139 & 0 & 0 & 7.139 \\
\hline Stage 2 & 5.925 & 10.398 & 0 & 16.323 \\
\hline Stage 3 & 4.866 & 3.398 & 8.417 & 16.681 \\
\hline \multicolumn{5}{|c|}{ Newly grown garnet (vol\%) } \\
\hline Stage 1 & 7.139 & 0 & 0 & 7.139 \\
\hline Stage 2 & 0 & 10.398 & 0 & 10.398 \\
\hline \multirow[t]{2}{*}{ Stage 3} & 0 & 0 & 8.417 & 8.417 \\
\hline & & & & Density \\
\hline \multicolumn{5}{|c|}{ Rock density (g/ccm) } \\
\hline Stage 1 & & & & 2.773 \\
\hline Stage 2 & & & & 3.048 \\
\hline Stage 3 & & & & 2.973 \\
\hline
\end{tabular}

minimum at $719^{\circ} \mathrm{C}$ and $9.65 \mathrm{kbar}$ and a final $v^{2,1}$ of $7.13 \mathrm{vol} \%$, with a $C_{0}$ value of $6.55 \times 10^{5}$ and $5.95 \mathrm{vol} \%$ of $\mathrm{Grt}_{2}$. The second minimization $\left(G_{2,2}^{2}\right.$ of $\left.4 \mathrm{vol} \%\right)$ converges to a minimum at $694{ }^{\circ} \mathrm{C}$ and $9.49 \mathrm{kbar}$ and a final $v^{2,1}$ of $4.35 \mathrm{vol} \%$ with a $C_{0}$ value of $4.44 \times 10^{5}$ and $9.44 \mathrm{vol} \%$ of $\mathrm{Grt}_{2}$. The third minimization $\left(G_{2,3}^{2}\right.$ of $5.57 \mathrm{vol} \%$ ) converges to a minimum at $707^{\circ} \mathrm{C}$ and $9.57 \mathrm{kbar}$ and a final $v^{2,1}$ of $5.86 \mathrm{vol} \%$ with a $C_{0}$ value of $2.46 \times 10^{5}$ and $7.53 \mathrm{vol} \%$ of $\mathrm{Grt}_{2}$. These results suggest that $\mathrm{Grt}_{2}$ is modeled between $694^{\circ} \mathrm{C}$ and $719^{\circ} \mathrm{C}$ and between 9.49 and $9.65 \mathrm{kbar}$. The increase in $T$ is associated with a decrease in resorption (from $2.78 \mathrm{vol}$ $\%$ to zero) and to a decrease in the fraction of $\mathrm{Grt}_{2}$ (from 9.44 to $5.95 \mathrm{vol} \%$ ). In this case different scenarios can be selected for the second stage. However, as discussed below (see Sect. 6.3), this solution is not the most likely based on the mineral inclusions captured during the growth of this first rim.

\subsubsection{Stage 2 - go fast mode}

The results for stage 2 discussed above show that the automated procedure selects the best solution at the end of optimization 1 and consequently can ignore a solution with different $P-T$ values. The go fast mode is used with initial $P-T$ being taken from $S_{1,2}^{2}$ at $650{ }^{\circ} \mathrm{C}$ and $16 \mathrm{kbar}$. The user defines moderate resorption to stabilize garnet at such conditions. The minimization converges to a minimum at $647^{\circ} \mathrm{C}$ and $15.95 \mathrm{kbar}$ and a final $v^{2,1}$ of $5.92 \mathrm{vol} \%$ with $C_{0}=8.12 \times 10^{6}$ and $10.40 \mathrm{vol}^{\circ} \mathrm{of} \mathrm{Grt}_{2}$. From a statistical point of view, this solution at higher $P$ is better than those found with the automated procedure (see Sect. 5.2.2). However, both $P-T$ conditions allow for precise modeling of the observed garnet compositions. In contrast to the low- $P$ solutions, the $P-T$ conditions obtained at high $P$ with and without resorption are similar $\left(\Delta T=0.37^{\circ} \mathrm{C}\right.$, $\Delta P=0.09$ kbar). In this case, resorption of $1.21 \mathrm{vol} \%$ of $\mathrm{Grt}_{1}$ improves the quality of the model and is selected as the most likely solution for stage 2 .

\subsubsection{Stage 3 - automated procedure}

For stage 3, the optimization is again divided into two steps: optimization1 and optimization2. During optimization 1, a fixed quantity of garnet $\mathrm{Grt}_{1}$ and $\mathrm{Grt}_{2}(5.92 \mathrm{vol} \%$ and $6.00 \mathrm{vol} \%$ ) is fractionated from the $C_{\mathrm{BR}}$. For $\mathrm{Grt}_{2}$ optimization 1 is carried out assuming $4.40 \mathrm{vol} \%$ resorption, the minimum required to stabilize garnet with a composition similar to $\mathrm{Grt}_{3}$. The first minimization $\left(G_{1,1}^{3}\right.$ of $\left.600{ }^{\circ} \mathrm{C}-8 \mathrm{kbar}\right)$ does not converge to a solution because the amount of garnet produced is too small $(1.8 \mathrm{vol} \%$ predicted whereas the minimum amount of $\mathrm{Grt}_{3}$ is fixed at $4 \mathrm{vol} \%$ observed in the sample). The second minimization $\left(G_{1,2}^{3}\right.$ from $600^{\circ} \mathrm{C}-16 \mathrm{kbar}$ ) converges to a minimum at $637^{\circ} \mathrm{C}$ and $13.33 \mathrm{kbar}$ for $C_{0}=1.71 \times 10^{4}$. A temporary solution $S_{1,1}^{3}$ is stored; $6.17 \mathrm{vol} \%$ of garnet is predicted stable at that stage. The third minimization $\left(G_{1,3}^{3}\right.$ from $800^{\circ} \mathrm{C}-8 \mathrm{kbar}$ ) does not converge because it predicts only $2.2 \mathrm{vol} \%$ of garnet, far below the minimum amount for 
$\mathrm{Grt}_{3}$. The fourth minimization converges to the same minimum as $S_{1,1}^{3}$ with a slightly smaller $C_{0}$ value of $1.62 \times 10^{4}$. A temporary solution $S_{1,2}^{3}$ is stored. The algorithm selects $S_{1,2}^{3}$ as the best solution based on the $C_{0}$ values $\left(S_{1, \text { best }}^{3}=S_{1,2}^{3}\right)$.

The $P-T$ conditions of initial guesses of optimization2 are fixed at $637^{\circ} \mathrm{C}$ and $13.33 \mathrm{kbar}$. Two new variables $v^{3,1}$ and $v^{3,2}$ are to be optimized; they correspond to the quantities of garnet $\mathrm{Grt}_{1}$ and $\mathrm{Grt}_{2}$ fractionated from the bulk composition during stage 3 . Three starting guesses are defined assuming either no more resorption than given by the input value $\left(v^{3,1}=5.92 \mathrm{vol} \%\right.$ and $\left.v^{3,2}=6.00 \mathrm{vol} \%\right)$, strong resorption $\left(v^{3,1}=4.00 \mathrm{vol} \%\right.$ and $\left.v^{3,2}=3.00 \mathrm{vol} \%\right)$, and moderate resorption $\left(v^{3,1}=4.96 \mathrm{vol} \%\right.$ and $v^{3,2}=4.50$ vol\%). In this case initial $v^{3,2}$ is set at $6.00 \mathrm{vol} \%$ whereas the volume fraction of $\mathrm{Grt}_{2}$ at stage 2 is $10.40 \mathrm{vol} \%$. As only a small volume fraction of $\mathrm{Grt}_{2}$ is preserved in the present-day sample (i.e., much less than was produced in stage 2), strong resorption is expected to occur during stage 3 . The first minimization converges to a minimum $\left(S_{2,1}^{3}\right)$ at $637^{\circ} \mathrm{C}$ and $13.33 \mathrm{kbar}$ and $v^{3,1}$ and $v^{3,2}$ of 5.92 and $6.00 \mathrm{vol} \%$ with $C_{0}=9.72 \times 10^{5}$ and $6.16 \mathrm{vol}^{2} \mathrm{Grt}_{3}$. The second minimization converges to a minimum $\left(S_{22}^{3}\right)$ at $632^{\circ} \mathrm{C}$ and $11.01 \mathrm{kbar}$ and $v^{3,1}$ and $v^{3,2}$ of 4.86 and $3.40 \mathrm{vol}$ $\%$ with $C_{0}=2.68 \times 10^{6}$ and $8.42 \mathrm{vol} \%$ of $\mathrm{Grt}_{3}$. The third minimization converges to a minimum $\left(S_{2,3}^{3}\right)$ at $637^{\circ} \mathrm{C}$ and $13.33 \mathrm{kbar}$ and $v^{3,1}$ and $v^{3,2}$ of 5.16 and $4.62 \mathrm{vol} \%$ with $C_{0}=5.89 \times 10^{6}$ and $8.27 \mathrm{vol}^{\circ} \mathrm{Grt}_{3}$. Two solutions are found at slightly different pressures $(13.37 \mathrm{kbar}$ and $11.01 \mathrm{kbar})$. The second solution $S_{2,2}^{3}$ is selected here because it is considered more likely based on the $C_{0}$ value and because it matches observed mineral proportions and textural observations better, suggesting stronger resorption of the first rim and core before crystallization of the second rim.

\section{Discussion}

\subsection{Intergranular diffusion and global equilibrium within domains}

In this study garnet growth is modeled based on $C_{\mathrm{BR}}$ and assuming thermodynamic equilibrium to be achieved at the millimeter scale. Component transport in the rock matrix through an intergranular medium is assumed to be fast relative to garnet growth, minimizing chemical potential gradients in the matrix. For the studied sample, compositional maps show that garnet in quartz-rich layers recorded a zoning that is similar to that in phengite-rich layers. Such observations and the excellent match of model compositions support the assumption of global equilibrium through an intergranular medium during each individual growth stage. Characteristic diffusion distance for $\mathrm{Al}$ in an intergranular medium saturated with hydrous fluid at $650{ }^{\circ} \mathrm{C}$ is $>1 \mathrm{~cm}$ for a time $>1 \mathrm{Myr}$ (Carlson, 2010), allowing for homogenization of the composition at the sample scale. However, it is well known that in some cases, porphyroblast growth can lead to development of local chemical heterogeneities generating changes in nutrient production rates (Carlson et al., 1995). In such cases, our model will not be suitable (Carlson et al., 2015), and a diffusion-controlled model should be used (see Konrad-Schmolke et al., 2005; Schwartz et al., 2011; Ketcham \& Carlson 2012).

\subsection{Heuristic search method and domains with local minimum}

As this study deals with non-linear problems (see Sect. 2.3) requiring a heuristic search method, the Nelder-Mead technique was selected (Nelder \& Mead, 1965). However, at the end of a single minimization it is not possible to ensure that the minimum found is the global minimum. One way to ensure that a convergence point is a global minimum is to map the objective-function with high $P-T$ resolution. An algorithm to compute such $P-T$ maps of $C_{0}$ and $L_{0}$ values for a given effective bulk composition is provided in GRTMOD.

As an example, the $C_{0}$ map in the $P-T$ range $500-900^{\circ}$ $\mathrm{C}$ and 5-20 kbar was computed for stage 1 using the $C_{\mathrm{BR}}$ (Fig. 8a,b). This map exhibits the shape of the cost function $C$ for stage 1 (see Sect. 5.2.1). Two distinct regions with local minima are found by the automated function: the first region at high $P\left(H P ; 674{ }^{\circ} \mathrm{C}, 17.49\right.$ kbar, $C_{0}=0.107$ ) and the second region at high $T$ $\left(H T ; 850-900{ }^{\circ} \mathrm{C}, \sim 6 \mathrm{kbar}, C_{0}<0.03\right)$. Every single minimization starting on one side of the ridge separating the two low regions (dashed line in Fig. 8a) converges to the HP domain. Those starting on the opposite flank of the ridge converge to the $H T$ domain. For stage 1 the automated procedure finds the global minimum within the $H T$ domain. This first example shows that the shape of such objective function can be complex. Hence it is crucial to run many successive minimizations from different starting guesses.

\subsection{Automated strategy [1]: limitation of multiple minima and solution finding}

Similarly, the $C_{0}$ map in the range $500-900{ }^{\circ} \mathrm{C}$ and $5-20$ kbar was computed for stage 2 , assuming no resorption of $\mathrm{Grt}_{1}$ (Fig. 8c,d). The effective $C_{\mathrm{BR}}$ is computed by subtracting from $C_{\mathrm{BR}}$ the amount of $\mathrm{Grt}_{1}$ produced during stage 1 . Two regions with local minima are found by the automated function during optimization1: one at $H T$ ( 3 solutions around $\sim 720{ }^{\circ} \mathrm{C}$ and $\sim 6.6 \mathrm{kbar}$ for a best $C_{0}$ of $\left.1.25 \times 10^{4}\right)$, and the other at $H P\left(647^{\circ} \mathrm{C}\right.$ and $16 \mathrm{kbar}$ with $C_{0}=4.15 \times 10^{4}$ ). In that case, only the second minimization converges toward $H P$ domain because the starting guess is located on the other flank of the ridge separating the two low regions. As the lower $C_{0}$ without resorption is found within the $H T$ domain, $647^{\circ} \mathrm{C}$ and 16 kbar are selected as starting guess for optimization2. In such a case, the $H P$ domain is not investigated during optimization 2 (i.e., with resorption) by the automated function. However, this can be done using the go fast mode (see Sect. 5.2.3). The results described 

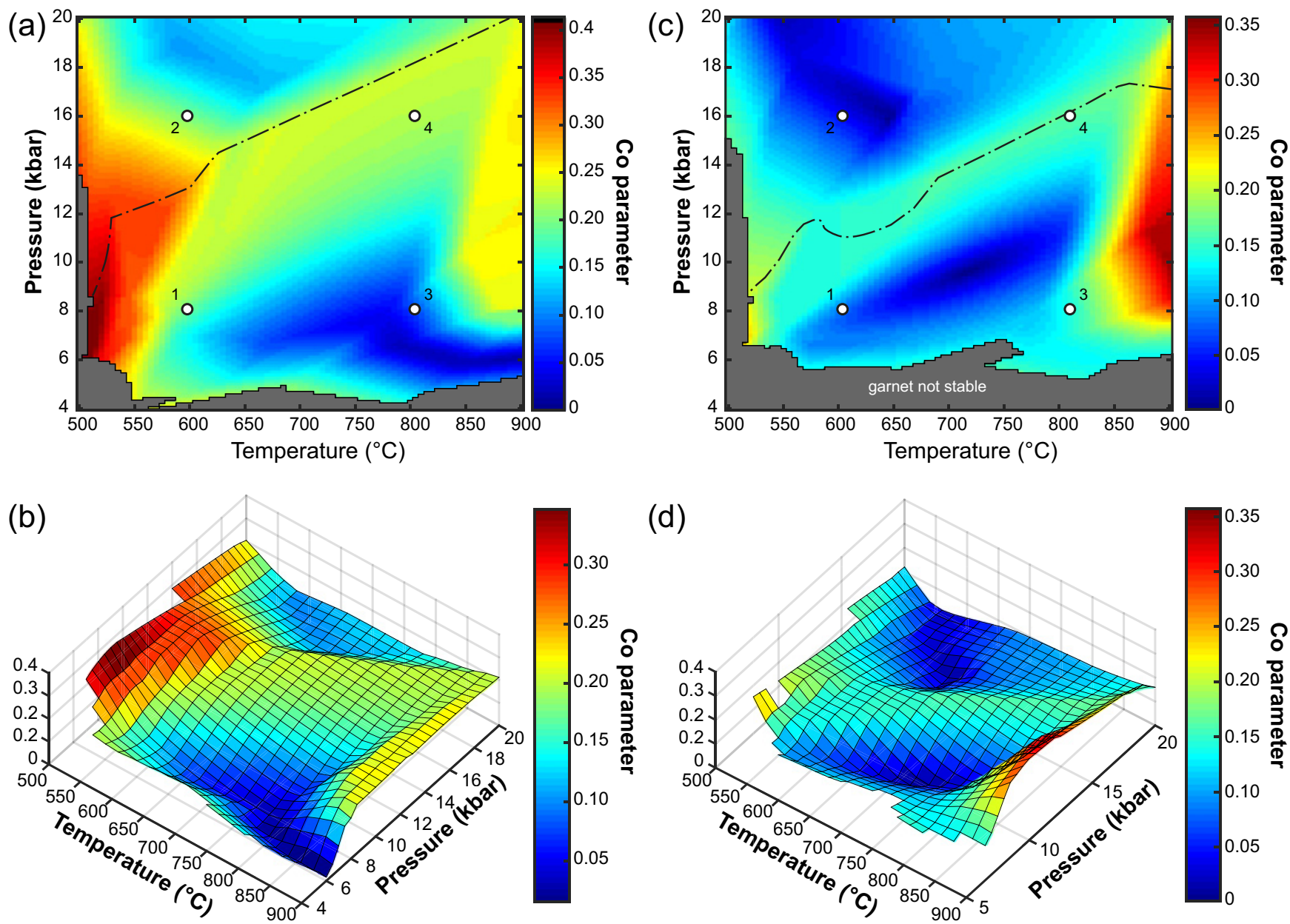

Fig. 8. 2D and 3D $P$ T maps of the cost function $C$ for stage $1(\mathrm{a}, \mathrm{b})$ and stage 2 without any resorption (c, d). The four starting guesses are reported in the 2D diagrams only. The dashed line outlines the ridge between the two low regions that show local minima (see text). (Online version in color.)

above demonstrate that for stage 2 the best solution from optimization $2\left(C_{0}=4.15 \times 10^{6}\right)$ is found in the $H P$ domain. The automated function converges to a local minimum, which has distinct $P-T$ conditions compared to those of the global minimum $(H P)$. However, there is little difference in $C_{0}$ between both solutions, and $\mathrm{Grt}_{2}$ composition can be accurately modeled at $720^{\circ} \mathrm{C} / 6.6 \mathrm{kbar}$ and $647^{\circ} \mathrm{C} / 16 \mathrm{kbar}$.

Stage 2 shows that garnet alone can provide ambiguous results in the framework of deriving $P-T$ conditions of one single metamorphic stage. In such cases, it is crucial to incorporate the study of the coexisting phases. For example, numerous inclusions of phengite in $\mathrm{Grt}_{2}$ suggest that it coexisted with Si-rich phengite $\left(\mathrm{Si}^{4+}=3.33 \pm 0.02\right.$ apfu, $X_{\mathrm{Mg}}=0.76 \pm 0.02$ ) (Table 5). The K-rich white-mica composition predicted by the model at $647^{\circ} \mathrm{C} / 16 \mathrm{kbar}$ is $\mathrm{Si}^{4+}=3.34$ and $X_{\mathrm{Mg}}=0.79$, whereas at $720^{\circ} \mathrm{C} / 6.6 \mathrm{kbar}$ it is $\mathrm{Si}^{4+}=3.17$ and $X_{\mathrm{Mg}}=0.68$. As expected, the Si content in phengite increases with increasing $P$. Modeled phengite composition nicely matches the measured composition at $647^{\circ} \mathrm{C}$ and $16 \mathrm{kbar}$. The study of coexisting phases, such as phengite in this example, strongly supports $\mathrm{Grt}_{2}$ growth during a $H P$ stage.
Table 5. Average composition and standard deviation of phengite.

\begin{tabular}{|c|c|c|}
\hline & $\begin{array}{l}\text { Phg } \\
\text { Average }\end{array}$ & $\begin{array}{lr}n & 280 \\
\text { St. Dev. }\end{array}$ \\
\hline $\mathrm{SiO}_{2}$ & 49.94 & 0.79 \\
\hline $\mathrm{TiO}_{2}$ & 0.28 & 0.03 \\
\hline $\mathrm{Al}_{2} \mathrm{O}_{3}$ & 28.54 & 0.45 \\
\hline $\mathrm{FeO}$ & 1.71 & 0.22 \\
\hline $\mathrm{MnO}$ & 0.22 & 0.11 \\
\hline $\mathrm{MgO}$ & 3.04 & 0.16 \\
\hline $\mathrm{CaO}$ & 0.49 & 0.08 \\
\hline $\mathrm{Na}_{2} \mathrm{O}$ & 0.62 & 0.11 \\
\hline $\mathrm{K}_{2} \mathrm{O}$ & 10.48 & 0.25 \\
\hline \multicolumn{3}{|c|}{ Structural formula (on a basis of 11 oxygen) } \\
\hline $\mathrm{Si}$ & 3.33 & 0.03 \\
\hline $\mathrm{Ti}$ & 0.01 & $<0.01$ \\
\hline $\mathrm{Al}$ & 2.25 & 0.03 \\
\hline $\mathrm{Fe}$ & 0.10 & 0.01 \\
\hline $\mathrm{Mn}$ & 0.01 & 0.01 \\
\hline $\mathrm{Mg}$ & 0.30 & 0.02 \\
\hline $\mathrm{Ca}$ & 0.03 & 0.01 \\
\hline $\mathrm{Na}$ & 0.08 & 0.01 \\
\hline $\mathrm{K}$ & 0.89 & 0.02 \\
\hline $\mathrm{XMg}$ & 0.76 & 0.03 \\
\hline
\end{tabular}




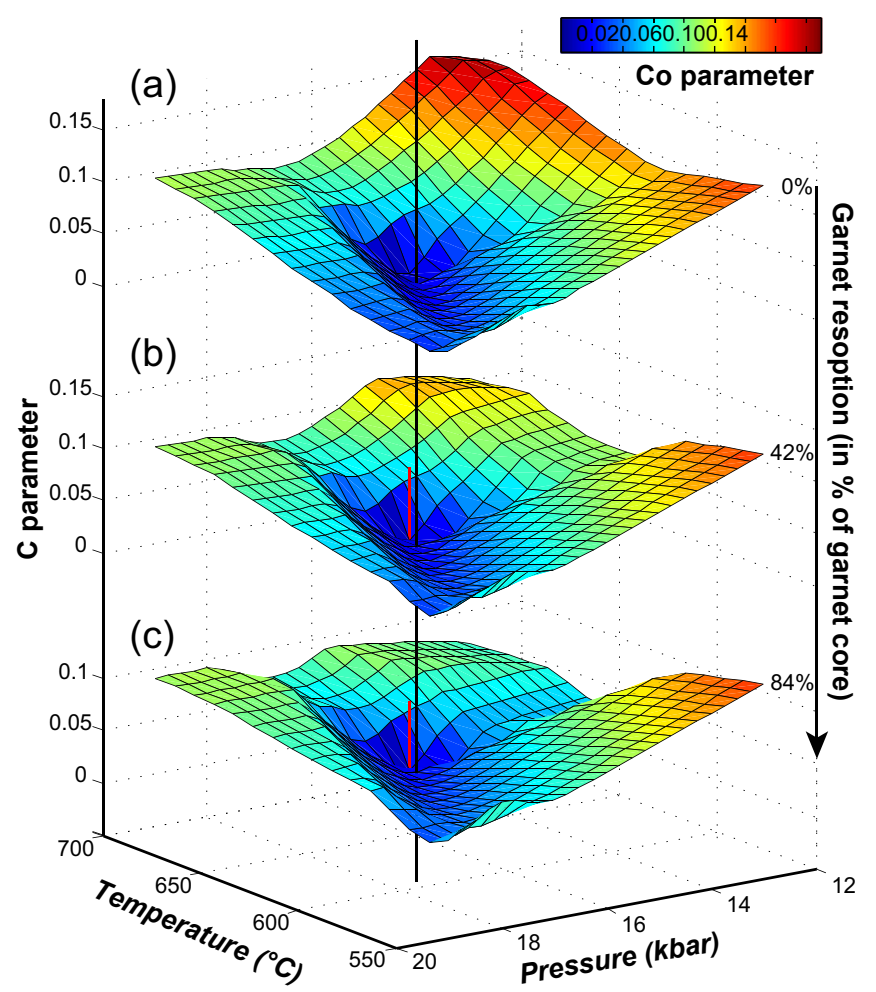

Fig. 9. 3D $P T$ diagrams of the cost function $\mathrm{C}$ for stage 2 with variable resorption (a $\quad 0 \%$, b $42 \%$, c $84 \%$ of garnet core). The black line marks the $P T$ position of the best solution from optimization1. The red lines mark the $P T$ position of the best solutions assuming moderate (42\%) and strong (84\%) resorption of garnet core. (Online version in color.)

\subsection{Automated strategy [2]: $P-T-X$ minimization}

The two-step optimization proposed in this study is expected to work when the shape of the objective function does not change significantly with garnet resorption. The investigated sample exhibits evidence of strong garnet resorption (Fig. 1) and is thus well suited to demonstrate the effectiveness of this automated method. The overall goal of optimization1 is to find out the best $P-T$ starting guess in a simple two-variable problem.

The $C_{0}$ maps in the $P-T$ range $550-700{ }^{\circ} \mathrm{C}$ and $12-20 \mathrm{kbar}$ were computed for stage 2 assuming $0 \%, 42 \%$ and $84 \%$ resorption of garnet core (Fig. 9). The $P-T$ position of the best solution from optimization1 (black line in Fig. 9) is very similar to values that assume intermediate and strong resorption (red lines in Fig. 9). This example demonstrates that, for a restricted $P-T$ range with a single minimum, the two-step optimization is an elegant strategy to solve the problem.

\section{5. $P-T$ stages recorded in garnet from a polymetamorphic micaschist}

The model predicts that garnet core $\left(\mathrm{Grt}_{1}\right)$ crystallized under granulite-facies conditions at $T>800{ }^{\circ} \mathrm{C}$ and $\sim 6$ kbar. This result is in line with other estimates available for the same area (Lardeaux \& Spalla, 1991; Rebay \& Spalla, 2001; Giuntoli, 2016). Such $H T /$ low- $P$ metamorphic conditions are common in the area and were recorded during the Permian (Rebay \& Spalla, 2001). The first rim $\left(\mathrm{Grt}_{2}\right)$ is Alpine and grew under eclogite-facies conditions $(650 \pm 50$ ${ }^{\circ} \mathrm{C}, 16 \pm 2.5$ kbar). Similar $H P$ conditions have been proposed for nearby areas of the Sesia Zone (e.g., KonradSchmolke et al., 2011; Regis et al., 2014). The model predicts $\mathrm{Grt}_{2}$ to grow at the expense of $\mathrm{Grt}_{1}$. The shape of $\mathrm{Grt}_{1}$ remnants with lobate edges supports this result. However, it is not possible to establish precisely when resorption occurred. It happened after stage 1 and either before or during stage 2 . The composition of Grt ${ }_{1}$ is very different from any observed in comparable rocks containing typical Alpine prograde garnet. The $P-T$ conditions obtained for $\mathrm{Grt}_{1}$ suggest that it formed at granulite-facies conditions, prior to Alpine orogeny, most likely during the Permian. At these $H T$ conditions, the protolith must have been largely dehydrated, hence a stage of rehydration must be invoked to explain the development of the mica-rich Alpine eclogite assemblage. A scenario of $H P$ hydration that triggered the dissolution of $\mathrm{Grt}_{1}$ and the precipitation of $\mathrm{Grt}_{2}$ seems plausible, and it may explain why substantial reaction overstepping (prior to hydration) occurred $\left(50-150{ }^{\circ} \mathrm{C}\right.$ and 2-4 kbar, depending on the prograde trajectory). The second Alpine rim $\left(\mathrm{Grt}_{3}\right)$ grew at lower $P$, estimated at $11 \pm 2 \mathrm{kbar}$ and $632 \pm 50^{\circ} \mathrm{C}$. The two solutions reported in Fig. 7 show similar $P-T$ ranges. This late stage may be associated with phengite rims and crossitic amphibole.

\subsection{Importance of incorporating resorption in thermodynamic models}

Our results from the textural analysis predict resorption of up to $36 \mathrm{vol} \%$ of the total garnet produced occurring at $>11$ kbar. During stage 3, the model implies that $70 \mathrm{vol} \%$ of $\mathrm{Grt}_{2}$ was resorbed. Such partial resorption has a strong effect on the effective $C_{\mathrm{BR}}$ used in modeling. It is fair to ask what a classical model would predict, such as those discussed in the introduction (Gaidies et al., 2008a; Konrad-Schmolke et al., 2008; Moynihan \& Pattison 2013; Vrijmoed \& Hacker 2014), all of which do account for fractionation of garnet, but only for the amounts produced, not those resorbed. The performance of such models has been tested using three different model variants:

- Model T-1 (Fig. 10b): This model is computed used Theriak and is based on fractionation $(100 \%$ of garnet produced) along a retrograde $P-T$ path involving five steps between $15.95 \mathrm{kbar}\left(647^{\circ} \mathrm{C}\right)$ and $11.01 \mathrm{kbar}\left(632^{\circ}\right.$ $\mathrm{C})$. These values were chosen based on thermobarometric results of this study (Fig. 10a) and on petrological evidence (e.g., phengite inclusions; see Sect. 6.3). The relict garnet core $\mathrm{Grt}_{1}$ was initially fractionated from the $C_{\mathrm{BR}}$ in order to generate a suitable effective bulk composition for stage 2 (Fig. 10b). A limitation of this test is that the $P-T$ trajectory was arbitrarily chosen. 

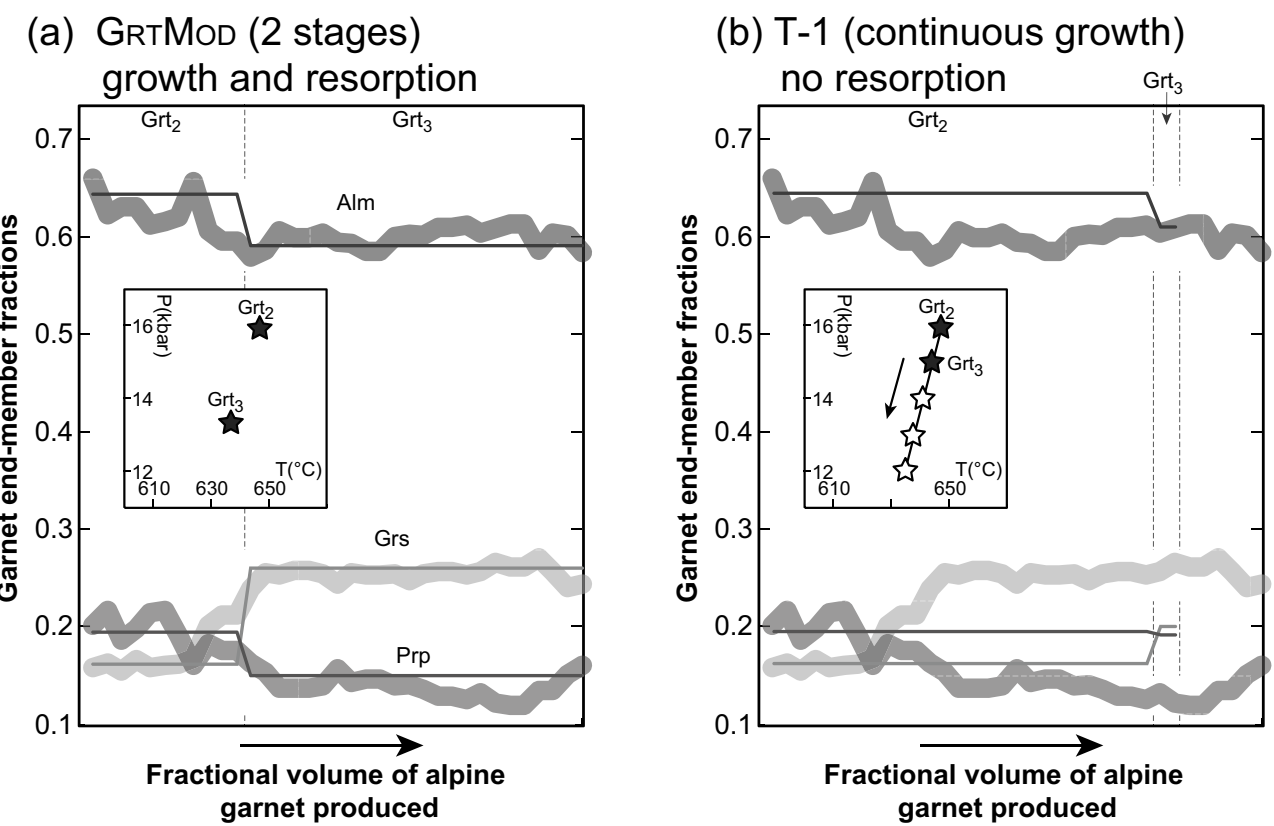

(c) MP-1 (P-T loop - 3 stages)
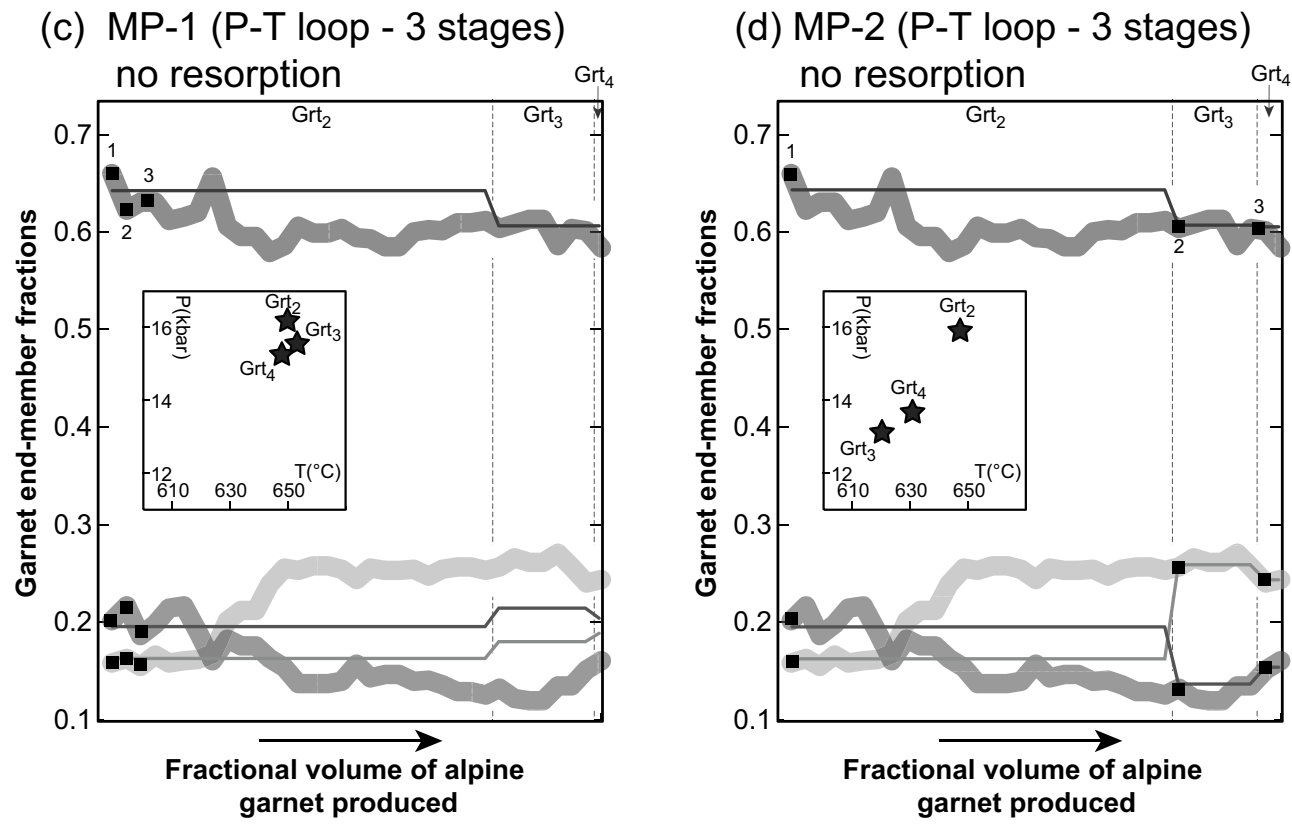

Fig. 10. Zoning profiles (thick lines) and model compositions (thin) for almandine, pyrope and grossular contents of the Alpine rims. The models were generated using (a) GRTMOD and the strategy described in this study, (b) Theriak along a fixed $P T$ loop from $15.95 \mathrm{kbar}$ (647 ${ }^{\circ}$ C) and $11.01 \mathrm{kbar}\left(632^{\circ} \mathrm{C}\right)$, and (c, d) GrTMod with a strategy similar to that of Moynihan \& Pattison (2013) (MP). In MP 1 , successive $P$ T optimization is done using the garnet composition of the next point on the zoning profile (black squares in c) without any consideration of the garnet volume produced. In MP 2, the successive $P T$ optimizations are done using the garnet composition of the point on the zoning profile that corresponds to the volume of garnet previously produced. For both cases $\sim 11$ vol\% of garnet is produced in three stages (labeled $\mathrm{Grt}_{2}, \mathrm{Grt}_{3}$ and $\mathrm{Grt}_{4}$ ). For each model, the $P T$ conditions are summarized in a small box. Zoning profiles of the Alpine rims in Fig. 2 are

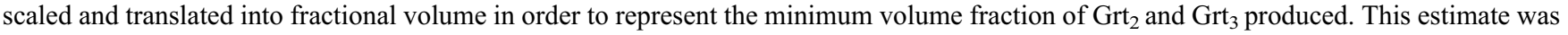
based on the compositional maps reported in Fig. 1 and on maps of other porphyroblasts from the same sample (Giuntoli, 2016).

- Model MP-1 (Fig. 10c): To avoid this arbitrariness, the strategy described by Moynihan \& Pattison (2013) was used. For the first composition of the zoning profile the best conditions $\left(P^{1}-T^{1}\right)$ are found, then a second point is analyzed and finds $P_{2}-T_{2}$, etc. For each step, the garnet model composition best matches the next point of the zoning profile. In MP-1, successive $P-T$ optimizations are performed using the garnet composition of the subsequent point of the zoning profile (black squares in Fig. 10c); however, the amount (volume) of garnet produced is not considered. 
- Model MP-2 (Fig. 10d): Same optimization as MP-1, but in this case the successive $P-T$ optimizations are done using the garnet composition of the point on the zoning profile that corresponds to the previously produced volume of garnet (black squares in Fig. 10d).

Models MP-1 and MP-2 were computed using GRTMOD with an option that prevents garnet resorption. In both cases $\sim 11 \mathrm{vol} \%$ of garnet is produced in three stages (labeled $\mathrm{Grt}_{2}, \mathrm{Grt}_{3}$ and $\mathrm{Grt}_{4}$ in Fig. 10c,d); this amount corresponds to the total volume of Alpine garnet found in the sample. Both models MP-1 and MP-2 retrieve the best $P-T$ path for the given modeling conditions. In model T-1, garnet is no longer predicted stable after the second $P-T$ step (for the local effective bulk composition).

The importance of considering resorption in forward thermodynamic models is evident when the results of the three classical models (with fractionation only) are compared with our reference model that includes resorption and fractionation. The reference model with two growth stages and partial resorption (GRTMOD in Fig. 10a) matches the observed zoning profile as well as the volume fractions of each growth zone. All of the classical models (T-1, MP-1 and MP-2) fail to reproduce the observed zoning profile. Furthermore, the fraction of $\mathrm{Grt}_{2}$ is always overestimated at the first stage of growth $(\sim 16$ kbar). For $\mathrm{Grt}_{3}$, the models MP-1 and MP-2 predict different $P-T$ scenarios. MP-1 implies $H P$ garnet because the model always tries to fit the first Alpine rim composition that is not satisfactory for the subsequent rims $\left(\mathrm{Grt}_{3}\right.$ and $\mathrm{Grt}_{4}$ in Fig. 10c). In contrast, model MP-2 does match the composition of $\mathrm{Grt}_{3}$ but the corresponding volume fraction is seriously underestimated, whereas $\mathrm{Grt}_{2}$ is overestimated. These discrepancies are caused by the absence of resorption. Nevertheless, the $P-T$ conditions predicted by MP-2 are similar to those of the reference model.

This simple example demonstrates how important it is to consider the volume of garnet, not only the shape of the compositional profile. By comparing predicted and observed volume fractions in the sample, the amount of growth and resorption can be estimated. For samples that experienced no resorption, the models tested here produce the same result (Fig. 6). Of course the com-parison between samples and models is limited since the amount of garnet remaining from each growth zone after subsequent resorption is only a minimum of the garnet produced at that stage. Therefore, the success of a model covering all stages of growth and resorption needs to be judged by comparing all of their compositions and modal amounts.

\section{Conclusions}

In this study, we provide a strategy and a computer program, GRTMoD, to model garnet growth through successive stages by minimizing differences between measured and modeled compositions as predicted for a given effective bulk composition. Gibbs free energy minimization is used to obtain the model results. During garnet growth, the previous growth zones can either be fractionated from the bulk rock composition or be partially resorbed.

The shape of the objective function may be complex, sometimes showing two distinct local minima at different $P-T$ conditions (see Fig. 8). An automated strategy is proposed, but the results strongly rely on the first $P-T$ optimization. The example with two solutions shows that it is crucial to compare the measured and model compositions of the coexisting phases as additional constraints.

The models described in this study rely on a detailed characterization of the compositions and texture of the studied samples. Standardized X-ray maps are used to constrain the average composition of each growth zone and to calculate the phase proportions.

The GRTMOD program was successfully used to model garnet growth conditions of a poly-metamorphic micaschist from the Sesia Zone (Western Alps). Garnet core records Permian $H T / L P$ metamorphic conditions, whereas rims are formed at $H P$ and $M P$ during the Alpine continental subduction.

Acknowledgements: The authors acknowledge fruitful discussions with Rob Berman, Christian de Capitani, A. Pourteau, S. Centrella and V. Laurent on ideas regarding thermodynamic modeling and/or GRTMOD. We also thank E. Duesterhoeft for adding new features to the program Theriak D. We acknowledge $H$. Vrijmoed and an anonymous reviewer for their helpful comments and suggestions. This work was supported by the Swiss National Science Foundation (project 200020-146175).

\section{Appendix 1: Automated strategy description}

\section{A1.1 Optimization1 $(P-T)$}

Optimization 1 is carried out within a $P-T$ window defined between $T_{\min }, T_{\max }, P_{\min }$ and $P_{\max }$ (Fig. 4a, commands TMIN, TMAX, PMIN and PMAX see Appendix 2). The values of $L_{0}$ and $C_{0}$ are set at $1 \mathrm{e}^{19}$ outside this $P-T$ window or if garnet is not stable. The minimum fraction of garnet to be stable during this stage is fixed by the estimated proportion in the present-day sample. During optimization1, garnet resorption is not allowed to change, and the volume fractions $v^{i, j=1: i}{ }^{1}$ of garnet stabilized during the previous stages are either entirely fractionated or partially fractionated from the bulk-rock composition. For advanced stages, the complete fractionation may generate extreme LEB compositions from which garnet become unstable in the Gibbs free energy minimization (KonradSchmolke et al., 2008). Four initial guesses are defined, as illustrated in Fig. $4\left(G_{1,1}^{i}, G_{1,2}^{i}, G_{1,3}^{i}, G_{1,4}^{i}\right)$. Additional 
initial guesses $\left(G_{1, r>4}^{i}\right)$ can be easily defined. The number of initial guesses defines how many minimizations are done.

For stage $S^{1}$ there are only two variables $P^{1}$ and $T^{1}$, hence optimization 2 is skipped. At the end of each minimization a new solution is defined if (1) $C_{0}$ is lower than STOL (see Appendix 1) and (2) if no previous solution exists with similar $P$ and $T$ (Fig. $4 \mathrm{~b}$ ). The $P-T$ couple is not stored as a new solution if pressure and temperature differences with existing solutions are within $T D I 1$ and $P D I 1$, respectively (see Appendix 2). In this case the program considers that both minimizations converged to the same minimum, and only the first is stored as a solution. By contrast, for stage $S^{i}>1$, all solutions are stored, and the $P-T$ couple with the smaller value of $C_{0}$ is selected to be used as starting guess during optimization2 (for example $S_{1,2}^{i}$ becoming $G_{2,1}^{i}$ in Fig. 4b).

\section{A1.2 Optimization2 $(P-T-X)$}

Optimization 2 is carried out for stage $S^{i}>1$ and the following ones. It involves $i-1$ additional compositional variables $v^{i, j=1: i}{ }^{1}$ corresponding to the volume fractions of previous garnet growth zones. Pressure and temperature conditions of the best solution $\left(S_{1 \text {,best }}^{i}\right)$ from optimization 1 are selected as initial guess $\left(G_{2 \text {,best }}^{l}\right)$. By contrast to optimization1, compositional variables allowing garnet resorption are introduced. The first initial guess is the exact solution of optimization 1 , without any resorption or with a fixed amount of resorption (Initial $v^{i, j} \rightarrow \max \left(v^{j}\right)$ ). The first minimization allows testing if resorption can help to get a smaller value of $C_{0}$ and therefore improve the quality of the solution. The second guess assumes very major resorption of previous garnet growth zones (Initial $v^{i, j} \rightarrow \min \left(v^{j}\right)$ ) and the third one an intermediate resorption $\left(\right.$ Initial $v^{i, j}=\min \left(v^{j}\right)+\frac{\max \left(v^{j}\right) \min \left(v^{\prime}\right)}{2}$ ). At the

end of each minimization a new solution is defined if $C_{0}$ is lower than STOL. The refinement phase is applied to all solutions.

\section{A1.3 Auto-refinement phase}

The auto-refinement phase aims to explore the $P-T$ local variability of the cost function in order to provide a relative uncertainty and to investigate the sensitivity of the model compositions. The $C_{0}$ value of the cost function is used because it intuitively represents the deviation between model and measured compositions. New $C_{0}$ values are iteratively computed around the solution across height directions $(D 1, D 2, \ldots, D 8$ in Fig. 5). The $P-T$ increments $\mathrm{d} T$ and $\mathrm{d} P$ are set using values defined in TDII and PDII (Appendix 1).

For a given solution $S_{2 . s}^{i}$ with a value $C o_{2 . s}^{i}$ and a tolerance $T C_{0}$ (defined in $R E S C$, see Appendix 1), across the direction $d$, the next $P-T$ point $n+1$ is calculated while the following criterion is met

$C o_{n+1}^{d}<C o_{2, s}^{i}+T C_{o}$.
The same procedure is repeated in all directions in order to derive uncertainty bars (Fig. 5). The uncertainty on the volume fraction of garnet stable at $P^{i}, T^{i}$ is estimated as the standard deviation of the volume fractions estimated at each point across all directions.

\section{A1.4 Go fast mode}

The go fast mode allows beginning optimization 2 from a different starting point in order to check for alterna-tive solutions. User defines the initial $P-T$ couple and the program skips optimization1. As described in Appendix A1.2, three initial guesses with different compositional variables $v^{i, j=1: i}{ }^{1}$ (no resorption, strong resorption and moderate resorption) are defined for optimization2.

\section{Appendix 2: GRTMoD main commands}

\begin{tabular}{|c|c|}
\hline THDB & Thermodynamic database \\
\hline SAMP & $\begin{array}{l}\text { Sample name or additional commands for theriak } \\
(* \ldots)\end{array}$ \\
\hline SYST & $\begin{array}{l}\text { Order of oxides used to define the bulk (command } \\
\text { BULK) }\end{array}$ \\
\hline BULK & $\begin{array}{l}\text { Composition of the bulk rock composition in } \\
\text { oxide weight percentage }\end{array}$ \\
\hline $\mathrm{NH}_{2} \mathrm{O}$ & $\begin{array}{l}\text { Moles of } \mathrm{H} \text { to be added to the bulk rock } \\
\text { composition }\end{array}$ \\
\hline STOL & Tolerance to select the result as a solution \\
\hline RESC & Tolerance used for the auto refinement stage \\
\hline SELS & Method used to select the solution \\
\hline SELP & Method used to plot the solution \\
\hline TOLX & Tolerance on the variable $\mathrm{X}$ used by fminsearch \\
\hline TOLF & $\begin{array}{l}\text { Tolerance on the function value used by } \\
\text { fminsearch }\end{array}$ \\
\hline DISP & Disp command of fminsearch \\
\hline TMIN & $T_{\min }$ \\
\hline TMAX & $T_{\max }$ \\
\hline PMIN & $P_{\min }$ \\
\hline PMAX & $P_{\max }$ \\
\hline TDI1 & $T$ steps first level \\
\hline TDI2 & $T$ steps second level \\
\hline PDI1 & $P$ steps first level \\
\hline PDI2 & $P$ steps second level \\
\hline
\end{tabular}

\section{References}

Berman, R.G. (1988): Internally consistent thermodynamic data for minerals in the system $\mathrm{Na}_{2} \mathrm{O} \mathrm{K} \mathrm{K}_{2} \mathrm{O} \mathrm{CaO} \mathrm{MgO} \mathrm{FeO} \mathrm{Fe}_{2} \mathrm{O}_{3}$ $\mathrm{Al}_{2} \mathrm{O}_{3} \mathrm{SiO}_{2} \mathrm{TiO}_{2} \mathrm{H}_{2} \mathrm{O} \mathrm{CO}_{2}$. J. Petrol., 29, 445522. (1990): Mixing properties of $\mathrm{Ca} \mathrm{Mg} \mathrm{Fe} \mathrm{Mn} \mathrm{garnets.} \mathrm{Am.}$ Mineral., 75, 328344.

Caddick, M.J., Bickle, M.J., Harris, N.B.W., Holland, T.J.B., Horstwood, M.S.A., Parrish, R.R., Ahmad, T. (2007): Burial and exhumation history of a Lesser Himalayan schist: recording the formation of an inverted metamorphic sequence in NW India. Earth Planet. Sci. Lett., 264, 375390. 
Caddick, M.J., Konopasek, J., Thompson, A.B. (2010): Preservation of garnet growth zoning and the duration of prograde metamorphism. J. Petrol., 51, 23272347.

Carlson, W.D. (2010): Dependence of reaction kinetics on $\mathrm{H}_{2} \mathrm{O}$ activity as inferred from rates of intergranular diffusion of aluminium. J. Metamorph. Geol., 28, 735752.

Carlson, W.D., Denison, C., Ketcham, R.A. (1995): Controls on the nucleation and growth of porphyroblasts: kinetics from natural textures and numerical models. Geol. J., 30, 207225.

Carlson, W.D., Pattison, S.R.M., Caddick, M.J. (2015): Beyond the equilibrium paradigm: How consideration of kinetics enhances metamorphic interpretation. Am. Mineral., 100, 16591667.

Cheng, H. \& Cao, D. (2015): Protracted garnet growth in high P eclogite: constraints from multiple geochronology and $P T$ pseudosection. J. Metamorph. Geol., 33, 613632.

de Capitani, C. \& Brown, T. (1987): The computation of chemical equilibrium in complex systems containing non ideal solutions. Geochim. Cosmochim. Acta, 51, 26392652.

de Capitani, C. \& Petrakakis, K. (2010): The computation of equilibrium assemblage diagrams with Theriak/Domino soft ware. Am. Mineral., 95, 10061016.

Duesterhoeft E. \& de Capitani C. (2013): Theriak D: an add on to implement equilibrium computations in geodynamic models. Geochem. Geophys. Geosyst., 14: 49624967.

Evans, T.P. (2004): A method for calculating effective bulk composition modification due to crystal fractionation in garnet bearing schist: implications for isopleth thermobarom etry. J. Metamorph. Geol., 22, 547557

Fuhrman, M.1. \& Lindsley, D.H. (1988): Ternary feldspar modeling and thermometry. Am. Mineral., 73, 201215.

Gaidies, F., Abart, R., de Capitani, C., Schuster, R., Connolly, J.A. D., Reusser, E. (2006): Characterisation of polymetamorphism in the Austroalpine basement east of the Tauern Window using garnet isopleth thermometry. J. Metamorph. Geol., 24, 451475 .

Gaidies, F., de Capitani, C., Abart, R. (2008a): THERIA G: a software program to numerically model prograde garnet growth. Contrib. Mineral. Petrol., 155, 657671.

Gaidies, F., de Capitani, C., Abart, R., Schuster, R. (2008b): Prograde garnet growth along complex $P T t$ paths: results from numerical experiments on polyphase garnet from the Wölz Complex (Austroalpine basement). Contrib. Mineral. Petrol., 155, 673688 .

Giuntoli, F. (2016): Assembly of continental fragments during subduction at HP: metamorphic history of the central Sesia Zone (NW Alps). PhD Thesis, University of Bern, $242 \mathrm{p}$.

Hunziker, P. (2003): The stability of tri octahedral $\mathrm{Fe}^{2+} \mathrm{Mg} \mathrm{Al}$ chlorite. A combined experimental and theoretical study. $\mathrm{PhD}$ Thesis, University of Basel, $162 \mathrm{p}$.

Keller, L.M., De Capitani, C., Abart, R. (2005): A quaternary solution model for white micas based on natural coexisting phengite paragonite pairs. J. Petrol., 46, 21292144.

Ketcham, R.A. \& Carlson, W.D. (2012): Numerical simulation of diffusion controlled nucleation and growth of porphyroblasts. J. Metamorph. Geol., 30, 489512.

Konrad Schmolke, M., Handy, M.R., Babist, J., O’Brien, P.J. (2005): Thermodynamic modelling of diffusion controlled garnet growth. Contrib. Mineral. Petrol., 149, 181195.
Konrad Schmolke M., O’Brien P.J., de Capitani C., Carswell, D.A. (2008): Garnet growth at high and ultra high pressure conditions and the effect of element fractionation on mineral modes and composition. Lithos, 103, 309332.

Konrad Schmolke, M., O’Brien, P., Zack, T. (2011): Fluid migration above a subducted slab: constraints on amount, pathways and major element mobility from partially overprinted eclogite facies rocks (Sesia Zone, Western Alps). J. Petrol., 52, 457486.

Lanari, P., Guillot, S., Schwartz, S., Vidal, O., Tricart, P., Riel, N., Beyssac, O. (2012): Diachronous evolution of the Alpine continental subduction wedge: evidence from $P T$ estimates in the Briançonnais Zone houillère (France Western Alps). J. Geodyn., 56 57, 3954.

Lanari, P., Riel, N., Guillot, S., Vidal, O., Schwartz, S., Pêcher, A., Hattori, K. (2013): Deciphering high pressure metamorphism in collisional context using microprobe mapping methods: application to the Stak eclogitic massif (NW Himalaya). Geology, 41, 111114.

Lanari, P., Vidal, O., De Andrade, V., Dubacq, B., Lewin, E., Grosch, E.G., Schwartz, S. (2014a): XMapTools: a MATLAB@ based program for electron microprobe $\mathrm{X}$ ray image processing and geothermobarometry. Comput. Geosci., 62, 227240.

Lardeaux, J.M. \& Spalla, M.I. (1991): From granulites to eclogites in the Sesia zone, Italian Western Alps: a record of the opening and closure of the Piedmont ocean. J. Metamorph. Geol., 9, 3559

Mäder, U.K. \& Berman, R.G. (1992): Amphibole thermobarometry; a thermodynamic approach. in "IGCP 304 Conference, Paper 92 1E”. Geological Survey of Canada.

Mäder, U.K., Percival, J.A., Berman, R.G. (1994): Thermobarom etry of garnet clinopyroxene hornblende granulites from the Kapuskasing structural zone. Can. J. Earth Sci., 31, 11341145.

Marmo, B.A., Clarke, G.L., Powell, R. (2002): Fractionation of bulk rock composition due to porphyroblast growth: effects on eclogite facies mineral equilibria, Pam Peninsula, New Cale donia. J. Metamorph. Geol., 20, 151165.

Meyre, C., de Capitani, C., Partzsch, J.H. (1997): A ternary solid solution model for omphacite and its application to geo thermobarometry of eclogites from the Middle Adula nappe (Central Alps, Switzerland). J. Metamorph. Geol., 15, 687700.

Moynihan, D.P. \& Pattison, D.R.M. (2013): An automated method for the calculation of $P T$ paths from garnet zoning, with application to metapelitic schist from the Kootenay Arc, British Columbia, Canada. J. Metamorph. Geol., 31, 525548.

Nelder, J.A. \& Mead, R. (1965): A simplex method for function minimization. Comput. J., 7, 308313.

Rebay, G. \& Spalla, M.I. (2001): Emplacement at granulite facies conditions of the Sesia Lanzo metagabbros: an early record of Permian rifting? Lithos, 58, 85104.

Regis, D., Rubatto, D., Darling, J., Cenki Tok, B., Zucali, M., Engi, M. (2014): Multiple metamorphic stages within an eclogite facies terrane (Sesia Zone, Western Alps) revealed by $\mathrm{Th} \mathrm{U} \mathrm{Pb}$ petrochronology. J. Petrol., 55, 14291456.

Robyr, M., Darbellay, B., Baumgartner, K. (2014): Matrix dependent garnet growth in polymetamorphic rocks of Sesia zone, Italian Alps. J. Metamorph. Geol., 32, 324.

Schwartz, J.O., Engi, M., Berger, A. (2011): Porphyroblast crystallization kinetics: the role of the nutrient production rate. J. Metamorph. Geol., 29, 497512.

Spear, F.S. \& Selverstone, J. (1983): Quantitative $P T$ paths from zoned minerals: theory and tectonic applications. Contrib. Mineral. Petrol., 83, 348357. 
Spear, F.S., Selverstone, J., Hickmott, D., Crowley, P., Hodges, K.V. (1984): P T paths from garnet zoning; a new technique for deciphering tectonic processes in crystalline terranes. Geology, 12, 8790.

Spear, F.S., Kohn, M.J., Florence, F.P., Menard, T. (1991a): A model for garnet and plagioclase growth in pelitic schists: implications for thermobarometry and $P T$ path determinations. J. Meta morph. Geol., 8, 683696.

Spear, F.S., Peacock, S.M., Kohn, M.J., Florence, F.P., Menard, T. (1991b): Computer programs for petrologic $P T t$ path calculations. Am. Mineral., 76, 20092012.

Stowell, H., Zuluaga, C., Boyle A., Bulman, G. (2011): Garnet sector and oscillatory zoning linked with changes in crystal morphology during rapid growth, North Cascades, Washington. Am. Mineral., 96, 13541362.
Tinkham, D.K. \& Ghent, E.D. (2005): Estimating $P T$ conditions of garnet growth with isochemical phase diagram sections and the problem of effective bulk composition. Can. Mineral., 43, 3550.

Vrijmoed, J.C. \& Hacker, B.R. (2014): Determining $P T$ paths from garnet zoning using a brute force computational method. Contrib. Mineral. Petrol., 167, 997.

Whitney, D.L. \& Evans, B.W. (2010): Abbreviations for names of rock forming minerals. Am. Mineral., 95, 185187.

Yardley, B.W.D. (1977): An empirical study of diffusion in garnet. Am. Mineral., 62, 793800 .

Received 20 January 2016

Modified version received 20 June 2016

Accepted 11 August 2016 